\title{
Seismic performance of a floating roof in an unanchored broad storage tank: experimental tests and numerical simulations
}

\author{
Stefano Caprinozzi, ${ }^{1}$ Fabrizio Paolacci, ${ }^{2}$ Oreste S. Bursi ${ }^{3}$ and Matjaž Dolšek ${ }^{1}$ \\ ${ }^{1}$ Faculty of Civil and Geodetic Engineering, University of Ljubljana, Slovenia \\ ${ }^{2}$ Department of Engineering, Roma Tre University, Rome, Italy \\ ${ }^{3}$ Department of Civil, Environmental and Mechanical Engineering, University of Trento, Trento, Italy
}

\begin{abstract}
Liquid steel storage tanks equipped with floating roofs are critical components of industrial facilities because they often store hazardous material. In the past, major earthquakes have caused large vertical displacements of floating roofs. Consequently, roof failure and/or content loss has occurred, which has seriously endangered the surrounding environment and community. Therefore, research interest in this topic remains high, giving rise to experimental campaigns and investigatory studies concerning both design and assessment approaches. Along these lines, the first part of this paper briefly introduces a shaking table test performed on a scaled steel storage tank equipped with a floating roof. This test provided useful experimental data about the vertical displacement histories of floating roofs subject to seismic loading. Subsequently, a simplified model and a refined finite element model aimed at simulating the shaking table test program are introduced and described. Relevant experimental and numerical outcomes are then presented and discussed. Finally, we performed a parametric study related to the simplified model to highlight the most relevant parameters involved. It is shown that both the refined finite element model and the simplified model were capable of simulating the roof vertical displacement histories observed in the shaking table test. The former model has higher fidelity but appears to be excessively time-consuming, whilst the latter is more suitable for risk assessment purposes.
\end{abstract}

Keywords: floating roof, broad storage tank, seismic analysis, shaking table test, simplified model, finite element model

\section{Introduction}

Steel storage tanks are commonly used in the oil, gas and chemical industries to store a wide variety of hazardous material. In general, storage tanks are very susceptible to earthquake-related damage because of the adverse effects of the contained liquid on tank walls (e.g. elephant foot buckling) and floating roofs (e.g. sloshing effects). Numerous anchored and unanchored liquid storage tanks have been severely damaged during major earthquakes, as reported in [1], [2], demonstrating that various floating roof failure modes can trigger loss of containment (LOC).

The floating roof of a storage tank is usually installed in such a way that it can freely move upward and downward [3]. This technology is necessary to securely reduce the evaporative loss of stored content. The movement of the floating roof is typically stabilized by an annular pontoon with a rubber gasket at the edge of the roof. This pontoon seals the contact between the inner surface of the tank wall and the floating roof. 
On the top surface of the roof, several fittings are installed to drain rain and control the roof, among other functions. [4].

Many authors, including [5]-[7], have introduced simplified models to investigate the seismic behaviour of steel storage tanks and their contents. Such models are often used for seismic risk analysis (e.g. [8]-[10]) due to their computational simplicity but most disregard the influence of floating roofs. For example, a procedure for estimating the seismic vulnerability of tank farms was introduced in [11]. Although the tanks investigated in [11] were equipped with floating roofs, roof failure modes were neglected. Furthermore, steel storage tanks have been assessed with particular emphasis on LOC [9]. In this case, the authors proposed an interesting approach for estimating a direct relationship between damage and LOC, but the effect of LOC due to large roof deformation was neglected.

Finite element (FE) models represent an alternative to simplified models. Due to the rapid development of computers, FE models are now frequently used for research purposes. These models have the advantage of allowing the direct modelling of floating roofs to evaluate their seismic response ([12]-[14]). However, performing seismic analyses of tanks with FE models is still extremely computationally demanding, which is not suitable for seismic risk analyses that require hundreds of simulations. Thus, it would be more convenient to use simplified models that directly account for the presence of a floating roof. Some authors have already introduced such simplified models ([15]-[17]), but insight into the seismic behaviour of steel storage tanks with floating roofs is indeed still limited, as demonstrated by the recent experimental campaign on real [18] and scaled models ([19]-[22]).

The goal of the study presented in this paper is to improve the understanding of the seismic behaviour of steel liquid storage tanks with floating roofs. The first objective is to simulate the seismic response of a floating roof using a simplified model involving the large deflection analysis proposed by Shabani et al. [23]. The second objective of the study is to simulate the seismic behaviour of a floating roof using a refined FE model based on Abaqus [24]. Finally, the study aims to compare the results of both models with observations from the shaking table test performed within the INDUSE-2-SAFETY project [19].

First, shaking table tests performed on a mock-up of a broad liquid storage tank with a floating roof are presented. Then, we describe the theoretical background for the dynamic analysis of a floating roof using a simplified model as well as the step-by-step implementation of the study's methodology. This is followed by a description of a refined FE model developed in Abaqus [24]. Next, we present the displacement response histories of the floating roof and compare them to the corresponding displacements obtained via the simplified models and the results of the shaking table test. Finally, the seismic response of the floating roof is investigated by a parametric study to better understand the influence of the most relevant parameters on the seismic response of a floating roof.

\section{Description of the shaking table test}

An extensive experimental campaign has been performed in 2017 within the European project INDUSE-2SAFETY in cooperation with CEA EMSI laboratory (Saclay, France) [19]. In particular, shaking table tests have been carried out on two steel storage tank typologies [19]. In this study, we refer only to the unanchored broad steel storage tank mock-up with a floating roof, (Fig. 1(a)), which has a diameter of $3 \mathrm{~m}$ and a tank's wall height of $0.868 \mathrm{~m}$. The mock-up was a reduced-scale model with a scaling factor of 1/18. The tank wall was made of SS304 steel with a uniform thickness of $1 \mathrm{~mm}$. Usually, the tank's wall has no 
uniform thickness being constructed by several courses with different thicknesses. However, for practical reasons, this was not possible and, during the construction of the testing specimen, it was decided to refer to the so-called equivalent uniform thickness of the real case study and scale down the latter by the scaling factor. This led to a uniform tank's wall thickness. The same material with the same thickness was also used for the bottom plate, which was welded to the cylindrical wall. The tank was filled with water up to $90 \%$ of the tank height $(0.781 \mathrm{~m})$ with a freeboard approximately $8.5 \mathrm{~cm}$ thick. The mechanical properties of the steel storage tank are summarized in Table 1.

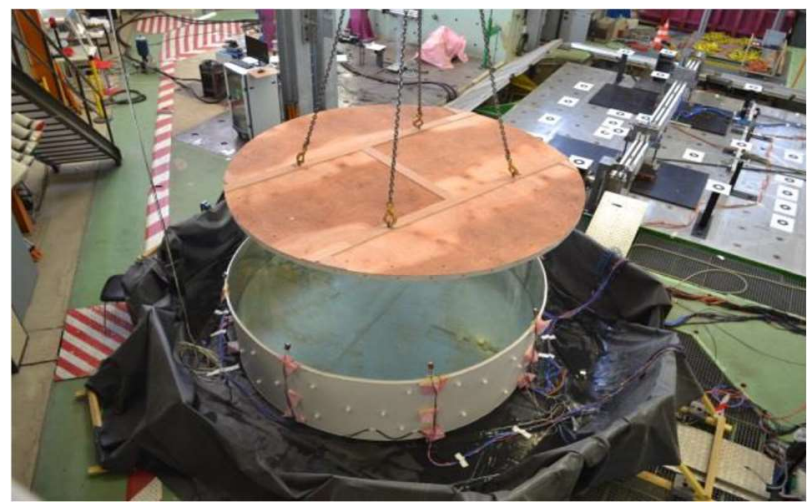

(a)

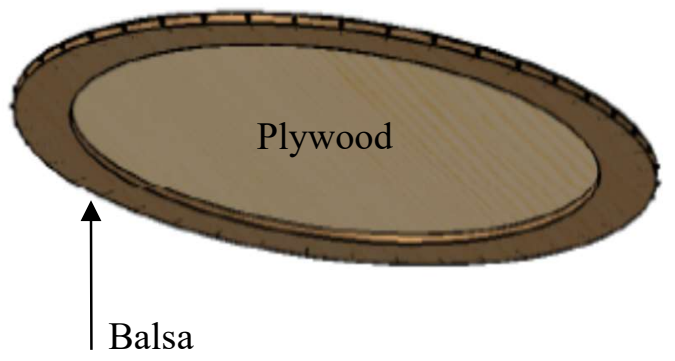

(b)

Fig. 1. (a) view of the tested specimen and (b) the floating roof model with the inner part made of 5 mm-thick plywood and the annular ring to which the $32 \mathrm{~mm}$-thick balsa was added.

Table 1 Tank material properties.

\begin{tabular}{cc}
\hline Young's modulus $\left[\mathbf{N} / \mathbf{m}^{2}\right]$ & $2.1 \cdot 10^{11}$ \\
\hline Poisson's ratio $[-]$ & 0.3 \\
\hline Density $\left[\mathbf{k g} / \mathbf{m}^{3}\right]$ & 7850 \\
\hline
\end{tabular}

The process of installing the floating roof of the tested specimen on the shaking table is presented in Fig. 1(a). The floating roof was made of two different types of timber, as schematically presented in Fig. 1(b). The base material was $5 \mathrm{~mm}$-thick plywood, which was used for the entire roof, while the pontoon was simulated with a $26 \mathrm{~cm}$-width annular ring of $32 \mathrm{~mm}$-thick balsa with the mechanical properties presented in Table 2. The outside diameter of the floating roof was slightly less $(2.98 \mathrm{~m})$ than the inner diameter of the steel storage tank $(3.00 \mathrm{~m})$. In order to reproduce the self-centring behaviour of the floating roof and to simulate the linear elastic contact between the floating roof and the inner side of the tank wall, 43 springs were placed radially in the annular ring as depicted in Fig. 2, which presents the section view of the annular ring.

Table 2 Mechanical properties of plywood and balsa.

\begin{tabular}{ccc}
\hline & Inner plate-plywood & Annular ring-balsa \\
\hline Young's modulus $\left[\mathbf{N} / \mathbf{m}^{\mathbf{2}}\right]$ & $7.8 \cdot 10^{9}$ & $1 \cdot 10^{9}$ \\
\hline Poisson's ratio $[-]$ & 0.26 & 0.38 \\
\hline Density $\left[\mathbf{k g} / \mathbf{m}^{3}\right]$ & 500 & 163 \\
\hline
\end{tabular}




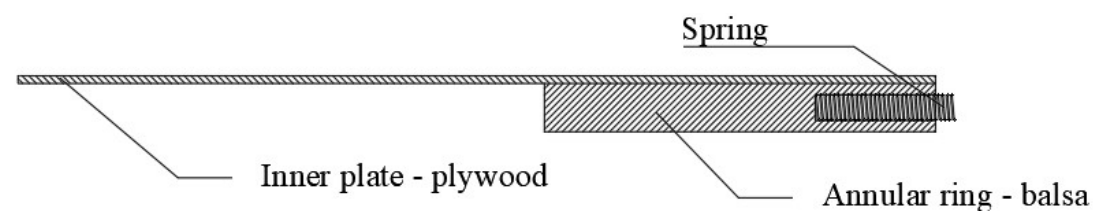

Fig. 2. Details of the installation of the floating roof spring.

In order to prevent damage to the shaking table's electronic instruments due to LOC, a rubber sheet (black) was placed between the bottom plate and the shaking table's surface as presented in Fig. 1(a). The presence of this insulating rubber sheet affected the friction coefficient $(\mu)$ between the steel storage tank and the shaking table. Its value was empirically estimated to be 0.11 , as reported in [19].

Many sensors were installed on the steel storage tank or the shaking table. Triaxial accelerometers were distributed across the outer surface of the tank to measure the acceleration distribution, taking into account the height of the tank and the angle around the tank axis (see Fig. 3(b)). Also, several pressure sensors were installed on the inner surface of the tank to acquire the pressure response history across the tank's entire height and circumference. Furthermore, vertical displacement sensors were installed on the tank base to monitor the presence of uplift. However, the floating roof was not equipped with measuring devices because its local response was not of particular interest. Only wave gauges were installed on the inner side of the tank wall. The eight wave gauges were radially spaced (as represented by red points in Fig. 3(a)). The wave gauges measured the wave height during the test. The triaxial accelerometer placed on the shaking table also provided useful information. In particular, the accelerometer measured the single horizontal component of the acceleration history (defined by the $0^{\circ}-180^{\circ}$ axis as presented in Fig. 3), which was used as a point of comparison with the numerical simulations.

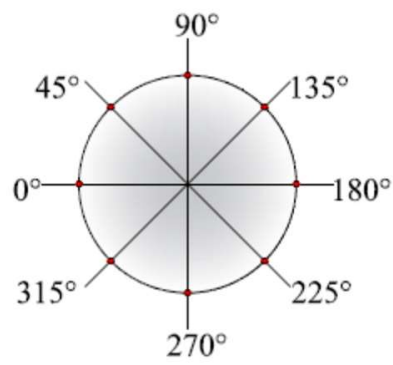

(a)

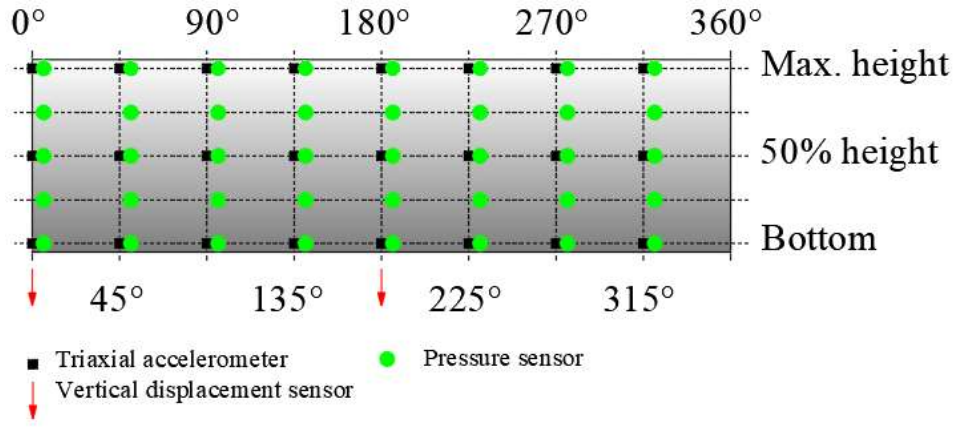

(b)

Fig. 3. Location of wave gauges (a) and triaxial accelerometer and vertical displacement sensors (b) in the tested steel storage tank.

\subsection{Experimental results}

Several ground motions with different scaling factors were used during the experimental campaign. However, for the present study, only the ground motion named "Düzce 29" was used because its frequency content strongly affected the sloshing motion of the floating roof. During the test, LOC occurred mainly due to overtopping. The uniaxial acceleration history recorder on the shaking table along the $0-180^{\circ}$ 
direction (see Fig. 3(a)) and the corresponding response spectrum are shown respectively in Fig. 4(a) and Fig. 4(b).

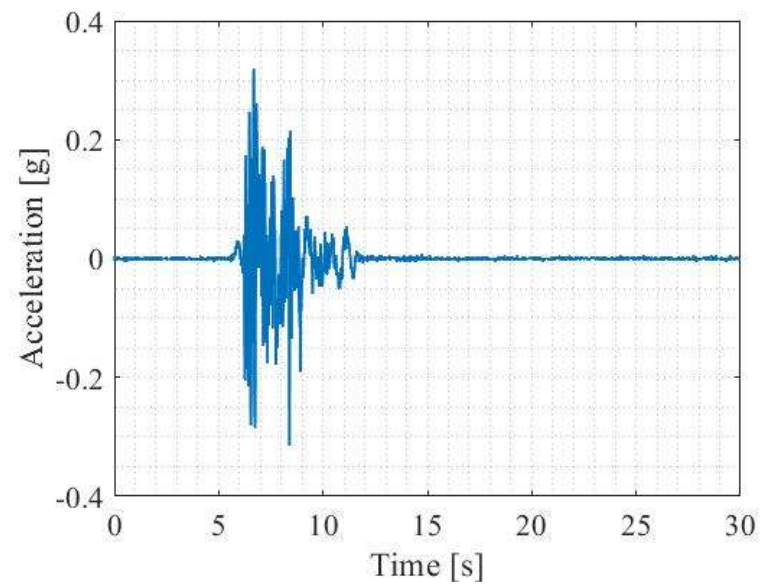

(a)

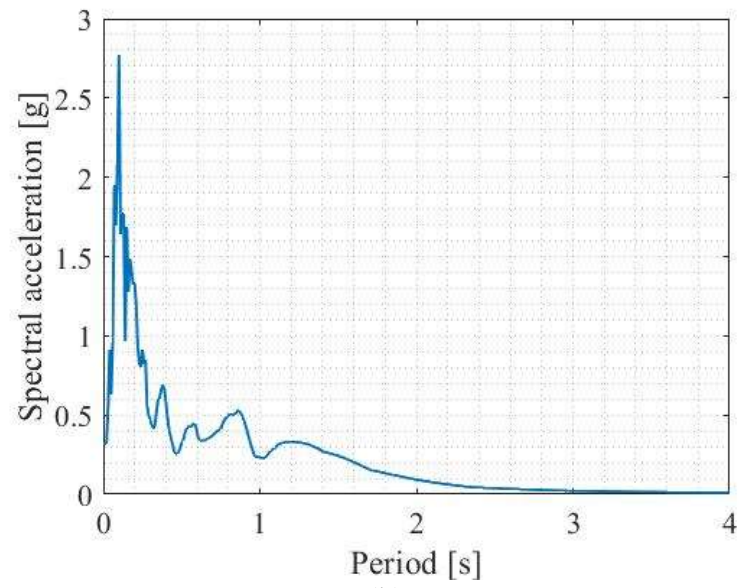

(b)

Fig. 4. (a) shaking table acceleration seismic record and (b) relevant acceleration response spectrum.

Fig. 5 shows an example of data recorded by the wave gauges installed on the inner wall of the steel storage tank (i.e. the wave gauges at the positions $0^{\circ}$ and $180^{\circ}$ ). The maximum wave height was about $10 \mathrm{~cm}$. Note that the upward wave movement corresponds to positive displacements, as shown in Fig. 5.

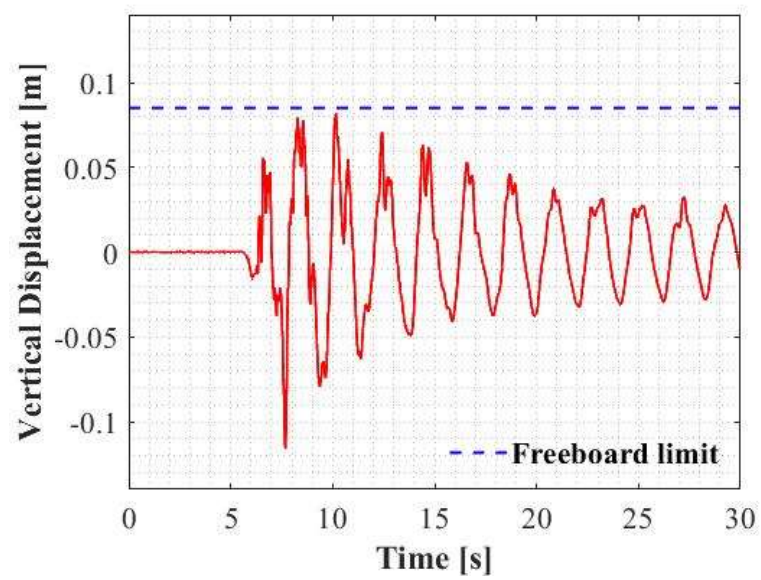

(a)

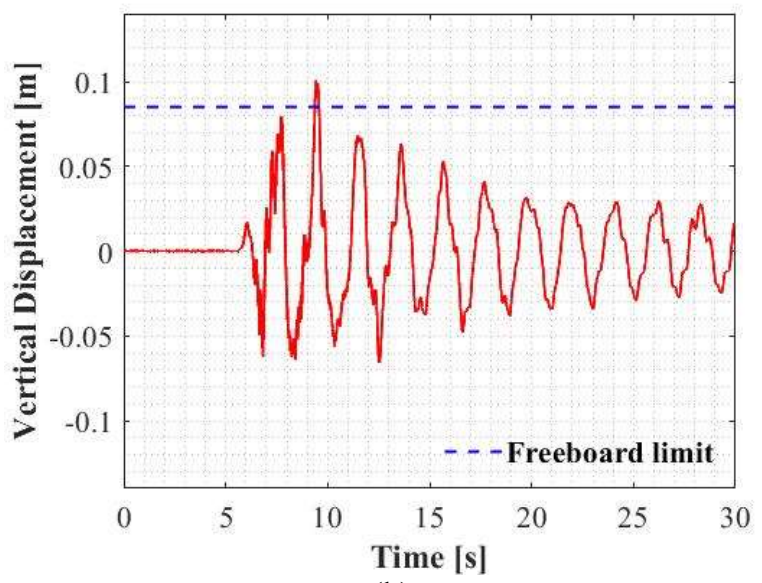

(b)

Fig. 5. Recorded wave height history from a shaking table test at (a) the position $0^{\circ}$ and (b) $180^{\circ}$ per Fig. 3 .

During the shaking table test, overtopping was observed [19], highlighted in yellow in Fig. 6. According to the data acquired and presented in Fig. 5(b), overtopping, represented by the total exceedance of the freeboard by the floating roof, appears to be only about $1.5 \mathrm{~cm}$. However, as earlier discussed, the roof itself had a thickness of approximately $4 \mathrm{~cm}$, with $3.2 \mathrm{~cm}$ of balsa plus $0.5 \mathrm{~cm}$ of plywood as shown in Fig. 2 and experimental evidences proved it totally exceeded the tank's top edge. Moreover, because of copious LOC occurred, higher wave heights were expectable. This misleading result reflects the difficulties encountered in performing the experimental test and the limitations of the sensors used, which are not capable of recording wave heights properly. Moreover, as presented in the previous section, 43 springs were installed within the annular ring. During the vertical floating roof displacement, once the roof 
exceeded the top edge of the steel storage tank, the springs popped out of place and obstructed the free movement of the floating roof, affecting the results.

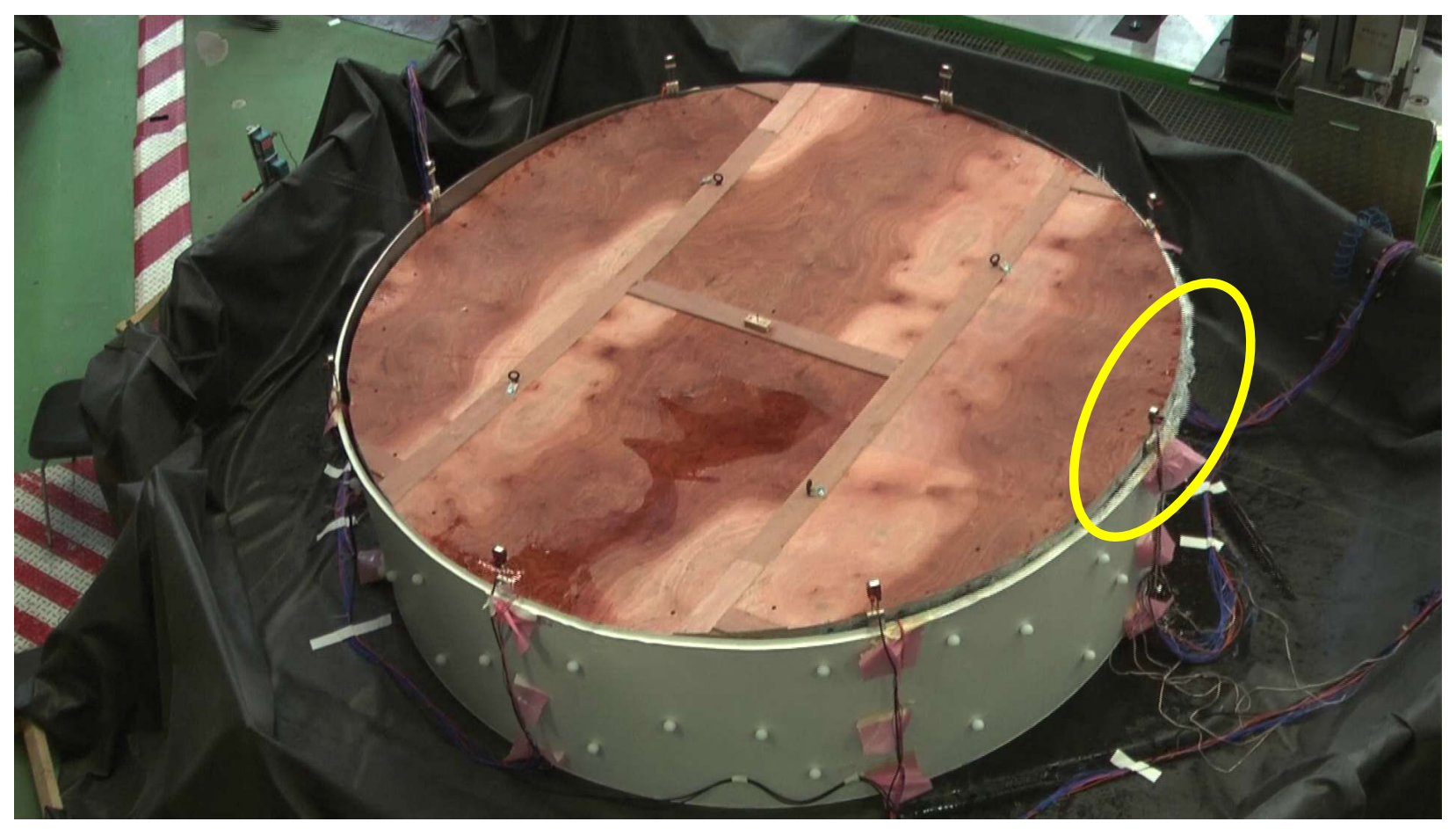

Fig. 6. Overtopping during shaking table testing.

\section{Formulation of the simplified model}

The simplified model used in the present work was already proposed in [23]. The authors derived the governing nonlinear equation of motion of the coupled floating roof-fluid system using Hamilton's variational principle, accounting for non-dissipative forces. In order to describe the floating roof-fluid Lagrangian the following assumptions were adopted:

- the tank's bottom plate and walls are supposed to be rigid;

- the fluid is assumed to be inviscid, incompressible and irrotational;

- the rocking of the rigid tank is not possible;

- no separation between fluid and roof is allowed (perfect contact);

- the floating roof is considered linear elastic.

Consequently, the Lagrangian of the system assumes the following form:

$\int_{t_{1}}^{t_{2}} L d t=\int_{t_{1}}^{t_{2}}(T-U+F) d t$

where $T, U$ and $F$ are the kinetic energy of the floating roof, the strain energy of the floating roof and the fluid Lagrangian. The fluid Lagrangian is considered as the energy of external forces. $T$ simply represents the energy needed to accelerate the floating roof mass from the rest state to a given velocity: 
$T=\frac{1}{2} \int m \dot{w}^{2}(t, r, \theta) d S_{v}$

where $S_{v}$ is the floating roof surface defined by the floating roof radius $r$, ranging from 0 to $R$, and $\theta$ is the angular coordinate in a polar reference system, ranging from 0 to $2 \pi$. The variable $m$ is the mass per unit area and $w$ is the vertical displacement of the floating roof plate, which, it is assumed, can be approximately simulated by the linear combination of time-invariant interpolation functions [23]:

$w(t, r, \theta)=\sum_{i=1}^{I} B_{i}(t) \xi_{i}(r, \theta)$

where $\xi_{i}$ is the $\mathrm{i}^{\text {th }}$ interpolation function (see Eqs. (A.2) - (A.3)), $B_{i}(t)$ is the corresponding time-dependent coefficient (i.e. displacement in generalized coordinates) and $I$ refers to the number of considered interpolation functions. Modal shapes of a free-edge thin circular plate have been assumed for the interpolation functions [25] (see Appendix).

$U$ in Eq. (1) represents the energy stored by the floating roof due to its deformation. By assuming the linear elastic response of the floating roof, its strain energy can be defined as [23]:

$U=\int_{0}^{2 \pi} \int_{0}^{R} \int_{\frac{-h}{2}}^{\frac{h}{2}}\left(\sigma_{r r} \varepsilon_{r r}+\sigma_{\theta \theta} \varepsilon_{\theta \theta}+\sigma_{r \theta} \varepsilon_{r \theta}\right) r d z d r d \theta$

where $\sigma_{r r}, \sigma_{\theta \theta}$ and $\sigma_{r \theta}$ are the stress tensor components of the floating roof deck in polar coordinates, $\varepsilon_{r r}$, $\varepsilon_{\theta \theta}$ and $\varepsilon_{r \theta}$ are the corresponding strain values, and $R$ and $h$ are the floating roof radius and thickness, respectively.

$F$ is the fluid Lagrangian, which represents the external energy of the floating roof. Therefore, it accounts for the kinetic energy due to the movement of the coupled system floating roof-fluid and the potential energy due to the vertical fluid wave displacement. The fluid Lagrangian computed at the floating rooffluid interface can be expressed in polar coordinates as [23]:

$F=\int_{0}^{2 \pi} \int_{0}^{R} \rho\left[-\frac{1}{2}\left(\frac{\partial \phi}{\partial z}\right)_{z=H} \phi+\frac{\partial w}{\partial t} \phi-\frac{g}{2} w^{2}\right] r d r d \theta$

where $\rho$ is the fluid density, $H$ is the fluid height (filling level), $w$ is the flexural displacement of the floating roof introduced in Eq. (3), $g$ is the gravity acceleration and $\phi$ is the potential function of the fluid. The first two terms in square brackets represent the kinetic energy of the fluid at the surface level, while the last term represents the potential energy of the surface. The potential function of the fluid $\phi$ must satisfy the Laplace equation for an irrotational fluid:

$\nabla^{2} \phi=0$

The function must also satisfy the related boundary conditions:

$\frac{\partial \phi}{\partial z_{z=H}}=\frac{\partial w}{\partial t} \quad$ on the fluid-floating roof contact surface

${\frac{\partial \phi}{\partial z_{z=0}}}=0 \quad$ on the bottom plate 
$\frac{\partial \phi}{\partial r_{r=R}}=\dot{x}_{g} \cos \theta \quad$ on the tank wall

where $\dot{x}_{g}$ is the ground velocity due to the ground motion. The boundary condition in Eq. (7) reflects the assumption of perfect contact between the fluid and floating roof, while Eq. (9) derives from the assumption of the rigid tank wall. Under these premises, the fluid potential can be derived as in [23]:

$\phi(t, r, \theta)=\left[r \dot{x}_{g}+\sum_{i=1}^{I} A_{k}(t) \frac{J_{1}\left(\frac{\epsilon_{i}}{R}\right) \cosh \left(\frac{\epsilon_{i}}{R} z\right)}{J_{1}\left(\epsilon_{i}\right) \cosh \left(\frac{\epsilon_{i}}{R} H\right)}\right] \cos \theta$

where $J_{1}$ is the Bessel function of the first kind of order one, $A_{i}(t)$ is the time-dependent modal amplitude, $z$ is the vertical coordinate for the fluid (zero at the bottom tank plate and equal to $H$ at the free surface height) and $\epsilon_{i}$ is the $\mathrm{i}^{\text {th }}$ root of the first derivative of the Bessel function of the first kind of order one (as in Eq. (A.15)).

By applying Hamilton's variational principle to the Lagrangian of the system (Eq.(1)), the governing nonlinear equation of motion of the coupled floating roof-fluid system can be obtained [23]:

$\left(\boldsymbol{P}+\rho \boldsymbol{T} \boldsymbol{S}^{-1} \boldsymbol{T}^{t}\right) \ddot{B}+(\boldsymbol{Q}+\rho g \boldsymbol{U}) \boldsymbol{B}+\chi \boldsymbol{B}^{3}=\rho \boldsymbol{G} \ddot{x}_{g}$

where $\boldsymbol{P}, \boldsymbol{Q}, \boldsymbol{S}$ and $\boldsymbol{\chi}$ are matrices of order $I \times I$ where $I$ represents the number of considered modes and $\boldsymbol{G}$ is a vector of size $I$. The components of $\boldsymbol{G}$ reflect the importance of each interpolation function, $\boldsymbol{P}$ represents the contribution of the mass of the floating roof to the mass of the system, $\boldsymbol{T S} \boldsymbol{S}^{-\mathbf{1}} \boldsymbol{T}^{\boldsymbol{t}}$ provides the contribution of the fluid mass due to the sloshing, $\boldsymbol{Q}$ is the floating roof stiffness matrix and $\boldsymbol{U}$ can be interpreted as an additional stiffness due to the fluid. $\boldsymbol{P}, \boldsymbol{Q}, \boldsymbol{S}, \boldsymbol{G}$ and $\chi$ are composed of different elements which are described in detail in the Appendix.

Eq. (11) can be seen as a conventional form of the equation of motion, which is expressed as

$M \ddot{B}+K B+\chi B^{3}=\rho G \ddot{x}_{g}$

where $\boldsymbol{M}$ and $\boldsymbol{K}$ are expressed as

$M=P+\rho T S^{-1} T^{t}$

$\boldsymbol{K}=\boldsymbol{Q}+\rho g \boldsymbol{U}$

Since Eq. (11) is derived according to Hamilton's principle, the effect of non-conservative forces is not accounted for in the governing nonlinear equation of motion (Eq. (12)). This can be overcome by adding the effect of viscous damping using the Rayleigh damping model [17]. As a consequence, the damping matrix $\boldsymbol{C}$ (Eq. (15)) is introduced as a linear combination of matrices $\boldsymbol{M}$ and $\boldsymbol{K}$ :

$\boldsymbol{C}=\alpha \boldsymbol{M}+\beta \boldsymbol{K}$

where coefficient $\alpha$ and $\beta$ are calculated according to the Rayleigh damping model by using a damping ratio $\zeta$. Eq. (12) can then be expressed as

$M \ddot{B}+\boldsymbol{C} \dot{B}+K \boldsymbol{B}+\chi \boldsymbol{B}^{3}=\rho \boldsymbol{G} \ddot{x}_{g}$ 
Eq. (16) represents the differential equation of motion for simulating the seismic behaviour of the floating roof in generalized coordinates $\boldsymbol{B}$.

The solution of the equation of motion has been derived by using a Matlab-based code [26]. The workflow of the developed software tool is presented in Fig. 7. The input data related to the tank, the roof and the content are the number of considered modes $I[-]$, fluid height $H[\mathrm{~m}]$, Poisson's ratio of floating roof material $v$, tank radius $R[\mathrm{~m}]$, floating roof thickness $h[\mathrm{~m}]$, Young's modulus of floating roof material $E\left[\mathrm{~N} / \mathrm{m}^{2}\right]$, the density of floating roof material $\rho_{r}\left[\mathrm{~kg} / \mathrm{m}^{3}\right]$, the density of fluid $\rho_{l}\left[\mathrm{~kg} / \mathrm{m}^{3}\right]$, the critical damping ratio $\zeta$ and gravity acceleration $g\left[\mathrm{~m} / \mathrm{s}^{2}\right]$. Input data are received by the matrix function (MF) which is a function designed to calculate matrices $\boldsymbol{M}, \boldsymbol{C}, \boldsymbol{K}, \boldsymbol{\chi}$ and the vector $\boldsymbol{G}$ from Eq. (16). However, to calculate all the presented matrices, the coefficients $\lambda_{j, p}, E_{j, p}, D_{j, p}$ and $\epsilon_{i}$ (Eqs. (A.4) - (A.12) - (A.15)) has to be defined. For this reason, the MF function calls the coefficient function $(\mathrm{CF})$, which returns all necessary coefficients.

The output of the MF function $(\boldsymbol{M}, \boldsymbol{C}, \boldsymbol{K}, \boldsymbol{\chi}$ and the vector $\boldsymbol{G})$ is the input for the run function (RF), which composes Eq. (16). In this step, it is necessary to also define the seismic action in terms of the ground motion acceleration history $\left(\ddot{x}_{g}\right.$ in $\left.[g]\right)$ with its time-sampling interval $(d t)$ in seconds.

To calculate the response history of vertical displacements (Eq. (3)), the location of the roof's vertical displacement has to be defined in polar coordinates. The variable $R P o s[\mathrm{~m}]$ represents the radial coordinate from 0 to floating roof radius $R$, and $P o s$ [rad] refers to the angular coordinate ranging from 0 to $2 \pi$. Positive values of kinematical quantities are defined on the direction $\pi-0$ (i.e. the direction $180^{\circ}-0^{\circ}$ in Fig. 3(a)).

Finally, the RF composes Eq. (16) and calls the equation solver function (ESF) which solves it. The ESF function incorporates ode45, a built-in Matlab differential equations solver [27] which is based on the work of Dormand et al. [28]. The ESF function returns the vector of generalized displacements $\boldsymbol{B}$ for each time step of the ground motion. The output is then post-processed within the RF to calculate the vertical displacement of the floating roof $w$ according to Eq. (3). Eq. (3) provides the vertical displacement history's coupling time-dependent coefficients $B_{i}(t)$ ( $\mathrm{i}^{\text {th }}$ element of column vector $\left.\boldsymbol{B}\right)$ and the interpolation functions $\xi_{i}$ (Eqs. (A.2) - (A.3)). Finally, the vertical displacement history of the floating roof at the required position is calculated and plotted. 


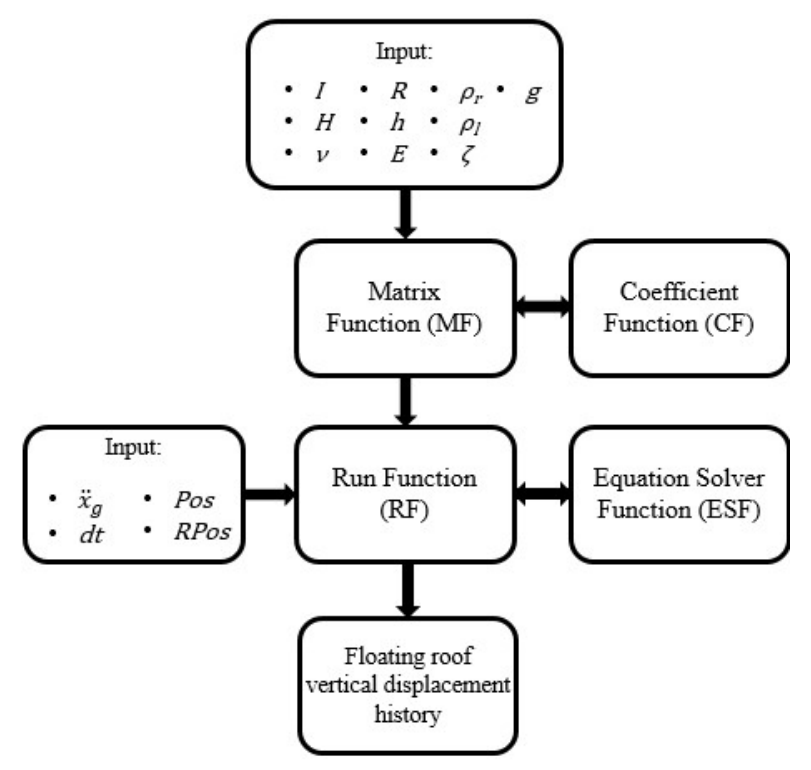

Fig. 7. Software tool workflow.

\section{Description of the refined finite element model}

The seismic response of the floating roof was also investigated with a refined FE model (Fig. 8), which was developed in Abaqus/Explicit [24] software. The model was developed in four parts, which were assembled in the assembly module of the software. Firstly, an analytical rigid surface was modelled to simulate the shaking table (Fig. 8). Although Abaqus supports several types of rigid surfaces (i.e. three-dimensional or two-dimensional, discrete or analytical), we decided to use a two-dimensional analytical rigid surface because the contact with the tank is in one plane and because discrete rigid surfaces are more computationally demanding, as reported in [24]. Moreover, the analytical rigid surface does not contribute to the rigid body's mass or inertia properties. All the nodes of the analytical rigid surface were constrained to the motion of the surface's reference node (RN) (see Fig. 8). Thus, the acceleration history measured on the shaking table during the test was directly imposed to the analytical rigid surface throughout the RN. Note that the ground motion (Fig. 4(a)) was imposed only in the X direction (Fig. 8) because the main objective of this study was to simulate the shaking table test. 


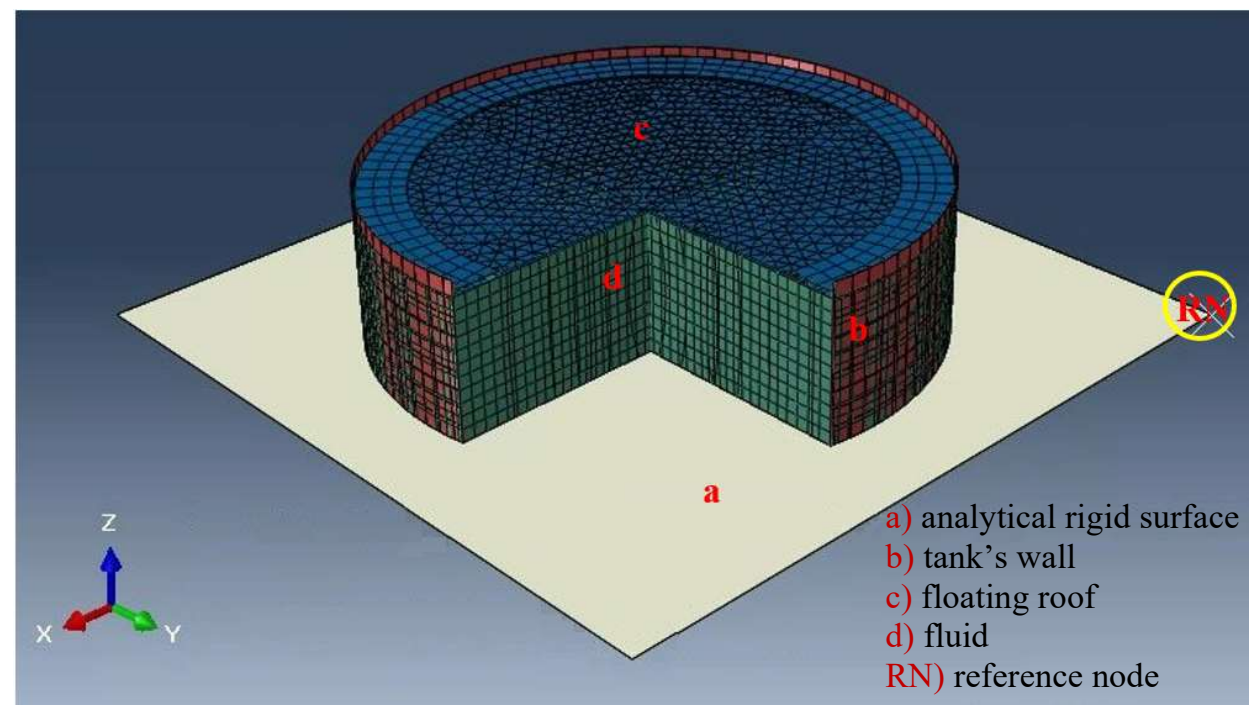

Fig. 8. Refined FE model of the broad tank.

The tank's wall and the bottom plate between the water and the rigid surface (Fig. 8) comprised the second part of the refined model and were modelled by fully-integrated S4 shell elements available in the Abaqus/Explicit library. This finite element is defined in the Abaqus' manual under "general-purpose shell elements" and was selected because it does not suffer the transverse shear locking problem. Additionally, this element has no unconstrained hourglass modes. Hence, no hourglass control is required in the bending and membrane response of the fully-integrated S4 element. Moreover, the S4 shell element is capable of providing robust and accurate solutions in all loading conditions for thin and thick shell problems. To reduce the computational time, the material of the steel storage tank was considered linear. Moreover, this assumption is supported by the fact that during the shaking table test no visible damage to the tank was observed. The properties of the steel are listed in Table 1.

The third part of the refined FE model is the floating roof (Fig. 8). It was modelled using the same shell elements used for the tank, but it was composed of two parts: the inner plate and the annular surrounding ring. Each part was modelled separately and then coupled. In both cases, the plywood and the balsa were modelled by linear elastic material, the properties of which are presented in Table 2 .

The water, which represents the fourth part of the model (Fig. 8), was modelled with the adaptive meshing technique. The adaptive meshing technique in Abaqus combines the features of pure Lagrangian and pure Eulerian formulations of the problem. This type of adaptive meshing is often referred to as Arbitrary Lagrangian-Eulerian (ALE) analysis. Since the sloshing mode caused a large amount of distortion in the solid element representing the fluid, we employed the automatical mesh refinement process supported by Abaqus [24] to ensure that the element itself had a smooth mesh. This process can be accessed in the ALE adaptive mesh domain menu by selecting the desired frequency and re-meshing sweep per increment. The frequency parameter mostly affects the mesh quality, while the re-meshing sweep per increment parameter defines when a new mesh is created by iteratively sweeping over the adaptive mesh domain, as discussed in the Abaqus users' manual [24]. Default values of the parameters are 10 and 1, respectively. The user can decide whether to improve the accuracy of the adaptive mesh by reducing the frequency and increasing the 
number of mesh sweeps performed in each adaptive mesh increment. However, this will affect the computational cost. In the present study, the default parameters were used.

The water was modelled by a three-dimensional solid element, C3D8R, which is a general-purpose brick element defined by eight nodes. In order to model the fluid static and dynamic behaviour, a hydrodynamic material model was needed. Thus, the material's volumetric strength was determined by an equation of state (EOS) provided for the content material (i.e. the water), which is supported by Abaqus/Explicit. However, the EOS can be defined in different ways. In the present model, a linear EOS was adopted. This EOS can be defined in the software by selecting the "Us-Up" type of EOS, which is the linear form of the Mie-Grüneisen EOS. This type of EOS proved to be particularly useful because it treats pressure as a function of the density and the internal energy per unit mass of the fluid. Internal energy is defined by the rate at which heat is added and the work done by stresses. However, if heat and stresses are neglected, the linear "Us-Up" can be defined [29]. The definition of the "Us-Up" EOS for the fluid modelled in this study required the selection of three parameters: the reference speed of sound in the medium $\left(C_{0}\right)$, the slope of the Us-Up curve $(s)$ and the Grüneisen ratio $\left(\Gamma_{0}\right)$ of the material. This EOS can also be applied to materials which have isotropic elastic or viscous deviatoric behaviour [30]. Furthermore, dynamic viscosity $(\mu)$ was provided to simulate the behaviour of water. Table 3 presents the properties of the water model. It is worth noting that material properties are temperature-dependent, and so the ambient temperature $\left(20{ }^{\circ} \mathrm{C}\right)$ was assumed. Note also that the water density $\left(\rho_{l}\right)$ and $\mu$ were selected according to Crittenden et al. [31], while $C_{0}$ was selected according to Cutnell et al. [32]. Finally, $s$ and $\Gamma_{0}$ were set to zero, as reported in the Abaqus examples manual.

Table 3 Properties of the FE model of water.

\begin{tabular}{cc}
\hline$\rho_{I}\left[\mathbf{k g} / \mathbf{m}^{3}\right]$ & 998.2 \\
\hline $\boldsymbol{\mu}[\mathbf{N} / \mathbf{m ~ s}]$ & $1.002 \cdot 10^{-3}$ \\
\hline $\boldsymbol{C}_{\boldsymbol{o}}[\mathbf{m} / \mathbf{s}]$ & 1482 \\
\hline $\boldsymbol{s}[-]$ & 0 \\
\hline $\boldsymbol{\Gamma}_{\boldsymbol{0}}[-]$ & 0 \\
\hline
\end{tabular}

Once all the parts of the model were created and assembled, it was necessary to carefully model the contacts between different parts of the model. Two categories of contacts were used in this model: the friction between the tank bottom plate and the shaking table and the frictionless contact between the tank contents and the tank and floating roof. Abaqus/Explicit offers various ways to model contacts. For friction and frictionless cases, the normal behaviour of the contact plane of two materials was modelled by "hard contact," which does not allow penetration of elements but does allow separation between the two materials. This feature can account for tank uplift. Concerning the tangential behaviour of the contact between the tank bottom plate and the shaking table, a friction coefficient of 0.11 was used, as discussed in Section 2. Zero friction was considered in the case of contacts between the water, the steel plates of the tank and the floating roof.

\section{Simulation of the shaking table test}

The seismic response of the floating roof was first simulated using the simplified model (introduced in Section 3). The input data of the model was partially presented in the previous sections. The height of the 
water $H$ and the tank's diameter $R$ are defined in Section 2, while $\rho_{l}$ is presented in Table 3 . The gravity acceleration $g$ was assumed to equal $9.81 \mathrm{~m} / \mathrm{s}^{2}$. The number of floating roof modes $I$ can affect the computational cost because the matrices size is $I \times I$, but as discussed by Hosseini et al. [33], the effects of higher modes are relatively unimportant for the estimation of the vertical displacement of the floating roof at the edge of the tank. Thus $I$ was assumed to equal three. The critical damping ratio $\zeta$ has to be carefully selected because it strongly affects the amplitude of the vertical displacement of the floating roof. In general, there are phenomena involved in the dynamic behaviour of a floating roof (i.e. friction between the annular sealing and the internal tank wall, floating roof impacts, etc. [34]) which can be at least approximately simulated by viscous damping. However, the quantification of the critical damping ratio is not straightforward. In the work of Nishi et al. [34], an experimental study on sloshing behaviour in a real tank showed how the damping ratio may vary with wave height. However, the authors considered $\zeta=2.5 \%$ to be an appropriate value to represent the maximum wave height. Thus, the same damping ratio was used for the present study's simplified model by adopting the classical Rayleigh damping model. Since the presence of the floating roof may significantly affect the first natural sloshing mode, while its stiffness has important effects only on higher modes [33], the first and third vibration modes of the floating roof have been considered to calibrate the Rayleigh coefficients.

In the simplified model, it was necessary to pay particular attention to the selection of the material properties of the floating roof. While the floating roof is generally composed of two different materials with different densities and thicknesses, the formulation of the model presented in Section 3 accepts only one value for each of these parameters. Thus, in the first attempt at model calibration, only the inner plate was considered, with its corresponding mechanical (Table 2) and geometrical properties (Section 2).

The vertical displacements of the floating roof at $0^{\circ}$ and $180^{\circ}$ are shown in Fig. 9(a) and Fig. 9(b), respectively, along with the experimental measurements of the wave gauges. In addition to the basic simplified model, which accounts for the floating plywood roof only, an additional model was developed. In this case, the characteristics of the floating roof approximated the effect of the plywood and balsa installed at the annular ring. Equivalent values for Young's modulus $E$ and Poisson's ratio $v$ were calculated as the volume-weighted mean of Young's moduli and Poisson's ratios of plywood and balsa, as suggested in [35]. This produced $E$ and $v$ values of $2.7 \cdot 10^{9}\left(\mathrm{~N} / \mathrm{m}^{2}\right)$ and 0.35 , respectively. Additionally, the equivalent thickness of the floating roof $h_{e}$ was also defined. First, the floating roof flexural stiffness $\left(R_{f}\right)$ was evaluated according to [36]:

$R_{f}=\frac{E h_{i p}{ }^{3}}{12\left(1-v^{2}\right)}+\frac{E I}{d}$

where $h_{i p}$ is the inner plate thickness, $I$ is the second moment of inertia of the annular ring section with respect to the middle axis of the inner plate, and $d$ is the floating roof diameter minus the annular ring width. Eq. (17) yielded a bending stiffness of approximately $2240 \mathrm{~N} / \mathrm{m}$. Equating Eq. (17) with the stiffness of an ideal homogeneous plate, the equivalent uniform thickness $h_{e}$ was determined to be approximately 2 $\mathrm{cm}$. This value was used for the recalculation of the equivalent density of the floating roof $\rho_{r}$ under the hypothesis of the invariance of the total mass.

The modified simplified model, which accounts for the effects of the plywood and the balsa, was subjected to ground motion recorded during the shaking table test campaign (Fig. 4(a)). Results are presented in Fig. 10(a) and Fig. 10(b), which are also compared with the experimental data, for $0^{\circ}$ and $180^{\circ}$ respectively. 


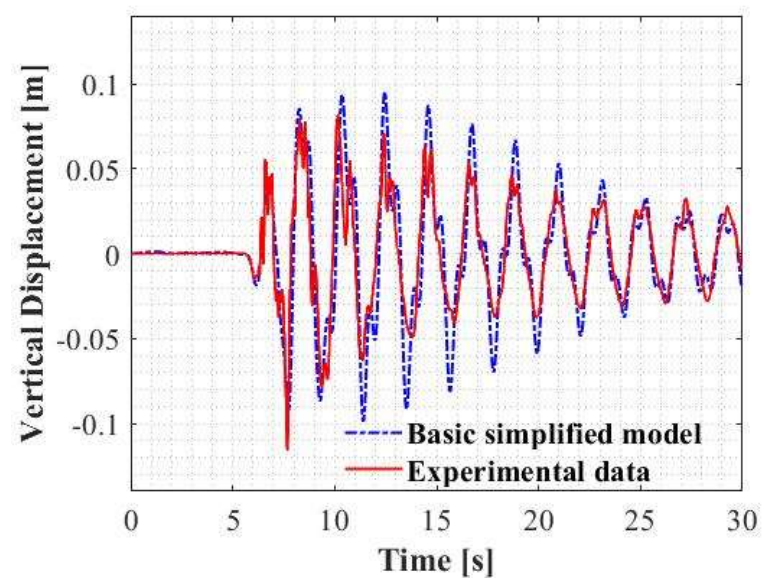

(a)

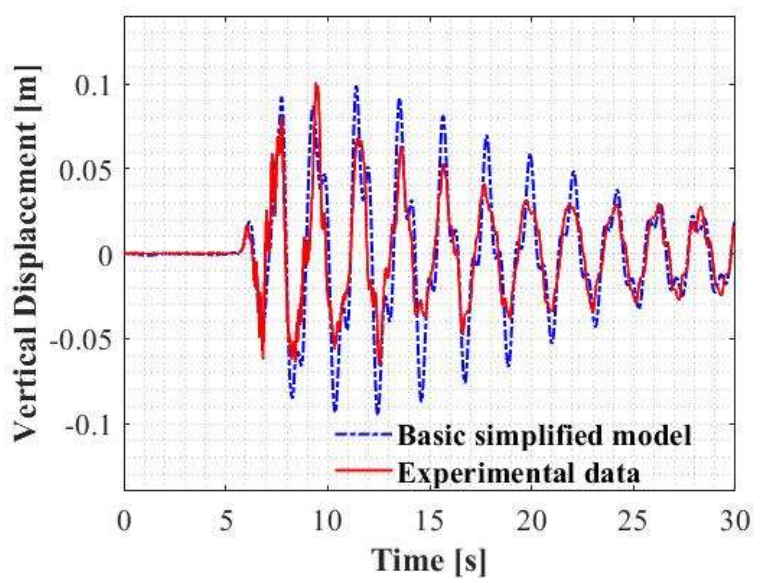

(b)

Fig. 9. Vertical displacement histories of the floating roof obtained by the basic simplified model at locations (a) $0^{\circ}$ and (b) $180^{\circ}$ (see Fig. 3(a)) and the corresponding experimental data from the shaking table test).

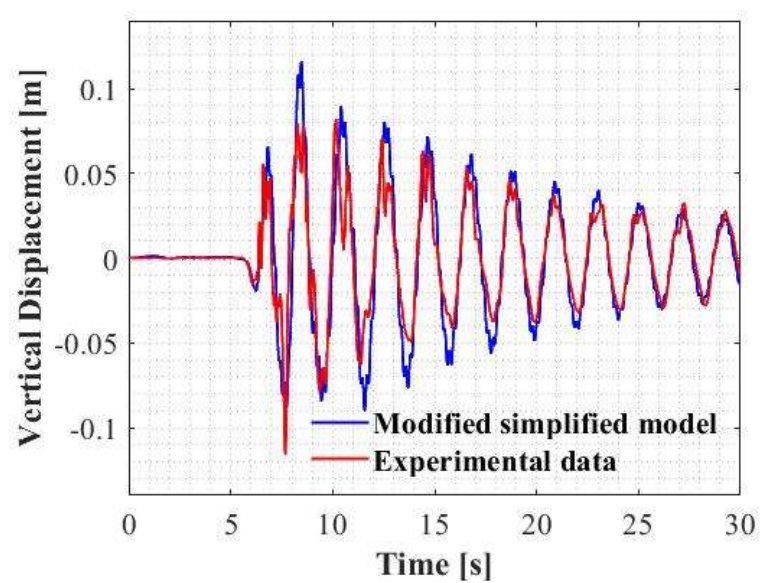

(a)

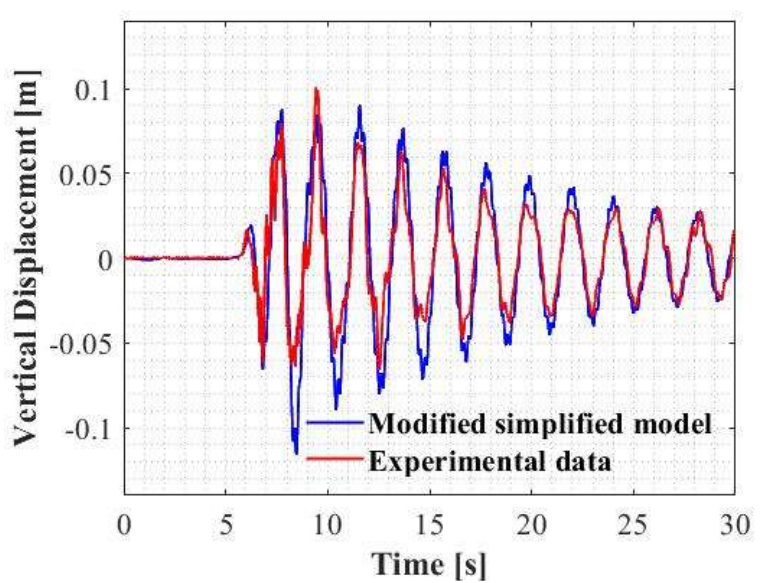

(b)

Fig. 10. Vertical displacement histories of the floating roof obtained by the modified simplified model at locations (a) $0^{\circ}$ and (b) $180^{\circ}$ (see Fig. 3(a)) and the corresponding experimental data from the shaking table test. The floating roof of the modified simplified model accounts for the effects of plywood and balsa.

The basic simplified model, which does not account for the influence of the annular ring, provided an excellent match with the experimental data in terms of phase for both the directions examined (Fig. 9(a) and Fig. 9Fig. 10(b)). This confirms that, for the present case study, the vertical fluid displacement is mainly driven by the first convective mode, which is largely affected by the ratio of the fluid height to the tank's radius. At the same time, an overestimation of vertical displacement due to an underdamped behaviour is appreciable mainly in the free vibration range (over 12 seconds). The reason for this behaviour is related to the damping approach adopted in the governing equation of motion (Eq. (16)). Indeed, in Eq. (16) a Rayleigh approach was introduced and a damping matrix (Eq. (15)), which is sensitive to the mass and stiffness of the floating roof, was defined. The failure to consider the presence of the annular ring led to the underestimation of the coefficients of the damping matrix. When the effect of the annular ring was included (Fig. 10 (a) and Fig. 10(b)), the simulation of the response history of vertical displacement was significantly improved, although the modified simplified model seemed to overestimate the maximum vertical displacement in comparison with the experimental results (see Fig. 10(a)). However, as previously 
presented in Section 2.1, conspicuous overtopping occurred during the shaking table test (Fig. 6) even though sensors were not able to properly capture it. This outcome seems to agree with the experimental test as can be observed in Fig. 6, where the photo presents the peak vertical displacement from the experiment, which is greater than that measured by the sensors.

Subsequently, the seismic response of the floating roof was simulated by the refined FE model developed in Abaqus [24]. To be consistent with the assumptions of the previously analysed model, the Rayleigh coefficients were assumed to be equal to those used in the simplified model. The results provided by the FE model were validated by the results of the shaking table test. The lateral displacement history in the $\mathrm{X}$ direction (i.e. the reference axis) is presented in Fig. 11(a) for the RN node of the analytical rigid surface and the central inner node of the tank bottom plate. It can be concluded that sliding did not occur between the steel storage tank model and the analytical rigid surface. The same was observed during the shaking table test, as recorded in the testing report [19]. The vertical displacement history of the steel storage tank bottom plate calculated at its edge at locations $0^{\circ}$ and $180^{\circ}$ (see Fig. 3) is presented in Fig. 11(b). This result indicates that tank uplift was negligible which is consistent with the observations from the test [19].

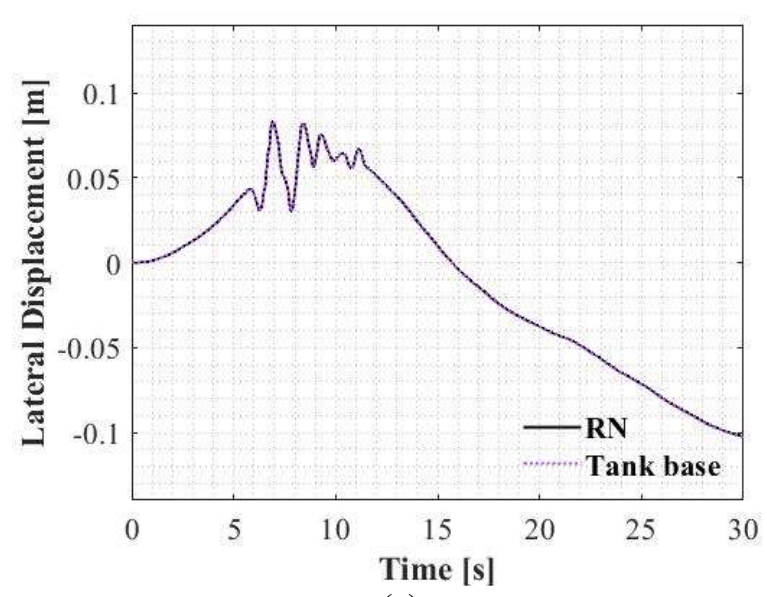

(a)

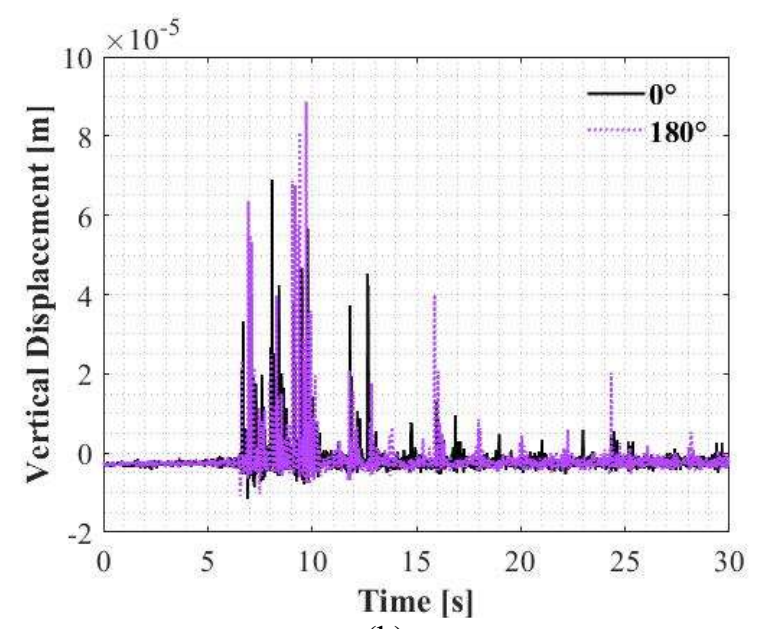

(b)

Fig. 11. (a) lateral displacement history in the $\mathrm{X}$ direction (i.e. the reference axis) for the $\mathrm{RN}$ node of the analytical rigid surface and the central inner node of the tank bottom plate, and (b) the vertical displacement history of the steel storage tank bottom plate calculated at its edge at locations $0^{\circ}$ and $180^{\circ}$.

Fig. 12(a) and Fig. 12(b) show the calculated vertical displacement history of the floating roof at $0^{\circ}$ and $180^{\circ}$, respectively, and compare this history to experimental data. The refined FE model allows the monitoring of both the floating roof and the liquid surface. The calculated vertical displacement of the floating roof and the wave height are shown in Fig. 12 and compared to the wave height measured during the shaking table test. Results displayed a close match with the experimental data obtained by the shaking table test. Indeed, as depicted in Fig. 12, a good in-phase behaviour is appreciable for both $0^{\circ}$ and $180^{\circ}$. The maximum vertical displacement seems to be overestimated, especially at $0^{\circ}$ (Fig. 12(a)), but such an outcome was expected, as discussed above. In the free vibration range of response (i.e. for timing over approximately 12 seconds), the response was overestimated, although the difference was on the order of a few centimetres. Only slight delamination between the floating roof and the liquid (the contents of the tank) was observed in the peaks of vertical displacement in the range of forced vibration (i.e. for timing less than approximately $12 \mathrm{~s})$. 


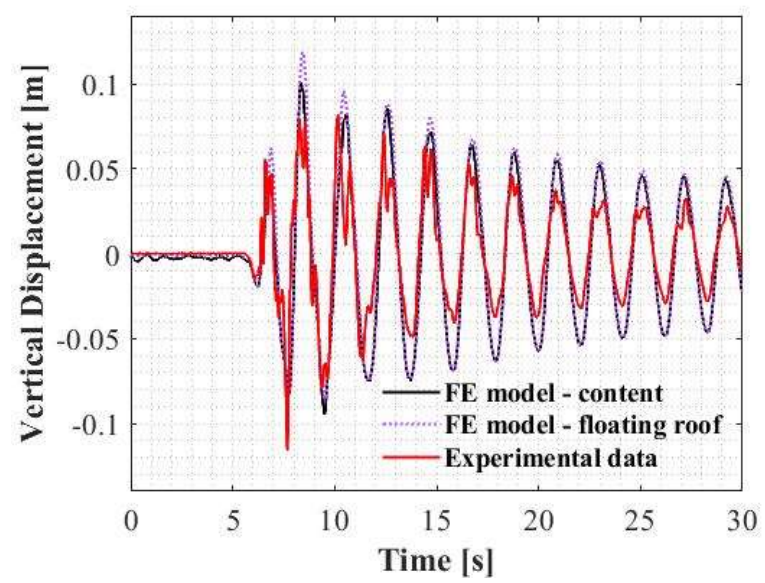

(a)

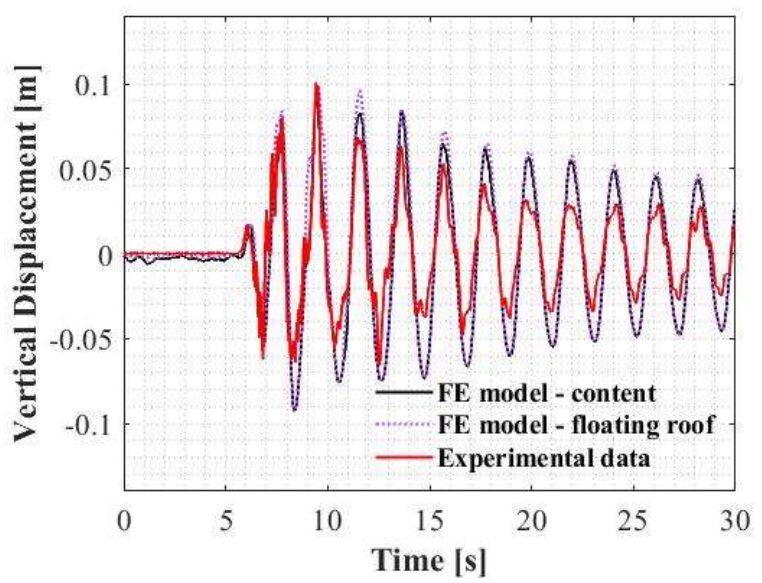

(b)

Fig. 12. Vertical displacement histories of the floating roof and the water wave calculated by the refined FE model and the vertical displacement of the content recorded during shaking table testing presented for the locations (a) $0^{\circ}$ and (b) $180^{\circ}$.

Moreover, the results of the refined FE model can also be used to check the impact of some assumptions used in the simplified model. For example, the assumption of perfect contact between the floating roof and the fluid, which was used in the simplified model, may not significantly affect the results obtained by the governing equation of motion (Eq. 16), although a gap of 1 to $2 \mathrm{~cm}$ was observed between the water and the floating roof (see Fig. 13(a) and Fig. 13(b)) in the time interval corresponding to forced vibration (6$12 \mathrm{~s}$ ). However, this vertical displacement gap tended to reduce as soon as the period of forced vibration ended. After this period, the gap of vertical displacement became practically negligible. Moreover, a perfect agreement in terms of the period can be appreciated between refined FE model outcomes and experimental evidence.

Finally, a comparison between the vertical displacement histories provided by both numerical models is provided in Fig. 13. The vertical displacement of the liquid surface produced by the refined FE model is also presented in Fig. 13.

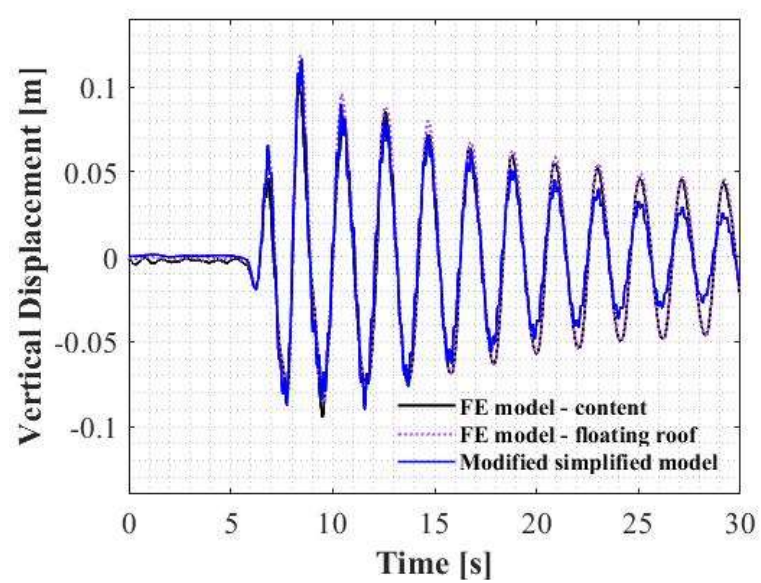

(a)

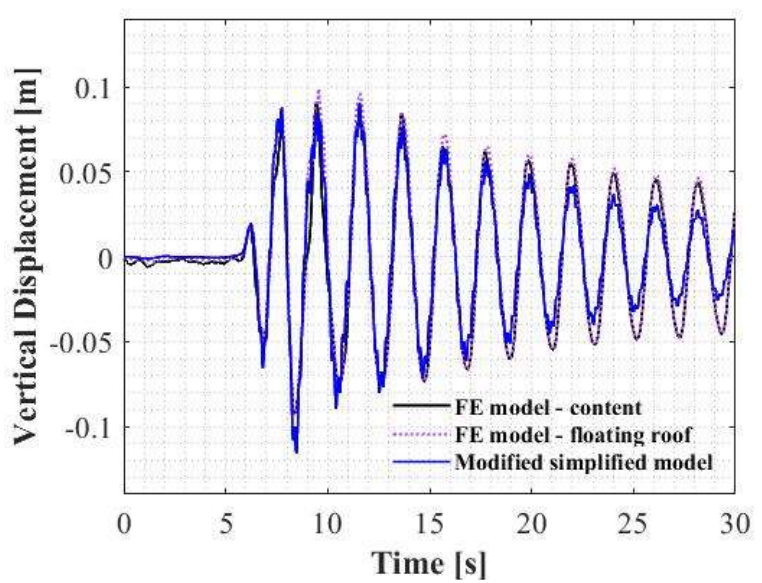

(b)

Fig. 13. Vertical displacement histories of the refined FE model and the modified simplified model at locations (a) 
$0^{\circ}$ and (b) $180^{\circ}$.

Both the simplified model and the refined FE model overestimate the maximum vertical displacement in comparison with the experimental results (Fig. 9(a) and Fig. 12(a)). However, as previously mentioned, conspicuous overtopping occurred during the shaking table test (Fig. 6). Therefore, the peak vertical displacement values obtained by both numerical models are in agreement with empirical observations (see Fig. 6). Moreover, by comparing the experimental data with the models' results, satisfactorily in-phase behaviour can be observed. This reflects an accurate mass and stiffness choices in the simplified model's input data and good modelling assumptions in the refined model. In this respect, it is worth emphasising that vertical floating roof displacement is mainly driven by the first sloshing mode, which is largely affected by the aspect ratio $(\gamma=\mathrm{H} / \mathrm{R})$ of the storage tank. Even in the free vibration range, the vertical displacement histories of both modelling approaches agree with each other and closely match the experimental data.

\section{Parametric analysis by the simplified model}

The seismic response of the floating roof was investigated through a parametric study of what input data has the greatest impact on the floating roof's vertical displacement. The modified simplified model, which accounts for the presence of the balsa annular ring, was used as the basic model in the parametric analysis. Each analysis was performed with the same ground motion adopted in the experimental campaign (Fig. 4(a)). The following parameters of the modified simplified model were varied:

- the aspect ratio of the tank $(\gamma=\mathrm{H} / \mathrm{R})$, which represents the ratio between the fluid height and the tank radius;

- the roof density $\rho_{r}$;

- Young's modulus of the floating roof $E$; and

- the content density $\rho_{l}$.

One parameter was varied at a time, while the other parameters maintained the same values used in the modified simplified model. The aspect ratio $\gamma$ was assumed to range between 0.1 and 1 and was used to investigate the influence of the filling level on the response. Roof density $\rho_{r}$ was assumed to range from 100 to $1000 \mathrm{~kg} / \mathrm{m}^{3}$ as presented in Table 5 . Some roof density values may be inapplicable to real tanks but were kept to investigate the influence of this parameter across a wide range of possible density values while keeping the plywood density as the median value of the selected range (see Table 2). Young's modulus is assumed to vary from $1 \cdot 10^{5}$ to $5 \cdot 10^{9}$ as presented in Table 5. Considering the plate stiffness formula (see Eq. (17)), the variation of $E$ can be interpreted as the variation of the thickness or both parameters. Therefore, only the Young modulus was varied. Content density $\rho_{l}$ ranges from 150 to $1050 \mathrm{~kg} / \mathrm{m}^{3}$ (Table 5). Even in this case, some values may be unrealistic but were kept in the parametric study to investigate potential nonlinear effects.

In the first input parameter variation, the objective was to calculate the maximum vertical displacement at location $0^{\circ}$ (see Fig. 3 ) and then compare the results $(w)$ with the maximum expected wave heights $\left(w_{e}\right)$ calculated according to the simplified procedure proposed in [7], which does not account for the effects of the floating roof. Results are presented in Table 4 together with the first convective period $T_{c}$ and the corresponding spectral acceleration $S_{e}\left(T_{c}\right)$. The results correspond to the edge of the floating roof (i.e. $r=$ 
R). The calculated vertical displacement history is also presented in Fig. 14(a). It can be observed that the greater the aspect ratio $\gamma$, the greater the vertical displacement. The maximum calculated vertical displacement corresponded to $\gamma=1$ and was about $18 \mathrm{~cm}$. This result is in agreement with the expected values obtained by the simplified procedure (Table 4). Moreover, an increase in the response period can easily be observed in the results of the modified simplified model (see Fig. 14(a)). This is most relevant for the free vibration motion, which begins after approximately 12 seconds. The reason for this behaviour is related to the large difference in the vibration mode most relevant to the sloshing. Indeed, by comparing the first convective period from $\gamma=1$ to $\gamma=0.1$ a period increase can be appreciated, which is also evident in Fig. 14(a).

Table 4 Influence of $\mathrm{H} / \mathrm{R}$ ratio on the maximum vertical displacement of the floating roof and the expected wave height estimated according to [7].

\begin{tabular}{ccccc}
\hline$\gamma[-]$ & $\boldsymbol{T}_{\boldsymbol{c}}[\mathbf{s}]$ & $\boldsymbol{S}_{\boldsymbol{e}}\left(\boldsymbol{T}_{\boldsymbol{c}}\right)[\mathbf{g}]$ & $\boldsymbol{w}_{\boldsymbol{e}}[\mathbf{m}]$ & $\boldsymbol{w}[\mathbf{m}]$ \\
\hline 0.1 & 4.23 & 0.01 & 0.014 & 0.011 \\
\hline 0.2 & 3.04 & 0.02 & 0.031 & 0.028 \\
\hline 0.3 & 2.55 & 0.04 & 0.054 & 0.044 \\
\hline 0.4 & 2.28 & 0.05 & 0.079 & 0.080 \\
\hline 0.5 & 2.12 & 0.07 & 0.110 & 0.110 \\
\hline 0.6 & 2.01 & 0.09 & 0.134 & 0.132 \\
\hline 0.7 & 1.95 & 0.10 & 0.152 & 0.147 \\
\hline 0.8 & 1.90 & 0.11 & 0.166 & 0.162 \\
\hline 0.9 & 1.87 & 0.12 & 0.176 & 0.172 \\
\hline 1 & 1.85 & 0.12 & 0.183 & 0.179 \\
\hline
\end{tabular}

Table 5 presents all the remaining parameters varied in the parametric analyses with their relative maximum vertical displacements $\left(w_{\rho r}, w_{E}\right.$ and $w_{\rho l}$ respectively) as calculated by the simplified model. The results are plotted in Fig. 14(b-d).

Fig. 14(b) shows the influence of $\rho_{r}$ on vertical displacement. The weak influence of the variation in $\rho_{r}$ can be observed. However, as $\rho_{r}$ increases, the vertical displacement increases as well, with a difference of 3.5 $\mathrm{cm}$ from $\rho_{r}=1$ to $\rho_{r}=10$. More significant is the shortening of the period, which is mainly evident after 12 $\mathrm{s}$ and is in the order of $10 \%$. The vertical displacements for several values of $E$, which are listed in Table 4, are shown in Fig. 14(c). It can be observed that the response is slightly affected by $E$. All the time-histories presented are in-phase with each other, which confirms that the dynamic response is mainly driven by the first convective mode of the liquid. Moreover, the influence of $E$ is excluded since it is a "rigid" mode (i.e. the first floating roof mode, see for instance Eq. (A.2)) that governs the response of the fluid. The impact of $\rho_{l}$ on vertical displacement is presented in Fig. 14 (d) (see also Table 5). As the $\rho_{l}$ the maximum vertical displacement decreases with an overall difference of approximately $4 \mathrm{~cm}$. A small phase shift can also be observed with an increase of the period of approximately $5 \%$ from $\rho_{l}=1$ to $\rho_{l}=10$.

Table 5 Parametric analysis input parameters and maximum vertical displacement observed.

\begin{tabular}{ccccccc}
\hline$\#$ & $\rho_{r}\left[\mathbf{k g} / \mathbf{m}^{3}\right]$ & $\boldsymbol{w}_{\rho r}[\mathbf{m}]$ & $\boldsymbol{E}\left[\mathbf{N} / \mathbf{m}^{2}\right]$ & $\boldsymbol{w}_{E}[\mathbf{m}]$ & $\rho_{l}\left[\mathbf{k g} / \mathbf{m}^{3}\right]$ & $\boldsymbol{w}_{\rho l}[\mathbf{m}]$ \\
\hline 1 & 100 & 0.135 & $1 \cdot 10^{5}$ & 0.083 & 150 & 0.147 \\
\hline 2 & 200 & 0.132 & $5 \cdot 10^{5}$ & 0.089 & 250 & 0.130 \\
\hline 3 & 300 & 0.137 & $1 \cdot 10^{6}$ & 0.094 & 350 & 0.127 \\
\hline
\end{tabular}




\begin{tabular}{ccccccc}
\hline 4 & 400 & 0.140 & $5 \cdot 10^{6}$ & 0.111 & 450 & 0.122 \\
\hline 5 & 500 & 0.139 & $1 \cdot 10^{7}$ & 0.126 & 550 & 0.123 \\
\hline 6 & 600 & 0.143 & $5 \cdot 10^{7}$ & 0.120 & 650 & 0.123 \\
\hline 7 & 700 & 0.149 & $1 \cdot 10^{8}$ & 0.100 & 750 & 0.121 \\
\hline 8 & 800 & 0.158 & $5 \cdot 10^{8}$ & 0.113 & 850 & 0.116 \\
\hline 9 & 900 & 0.164 & $1 \cdot 10^{9}$ & 0.116 & 950 & 0.121 \\
\hline 10 & 1000 & 0.170 & $5 \cdot 10^{9}$ & 0.113 & 1050 & 0.111 \\
\hline
\end{tabular}

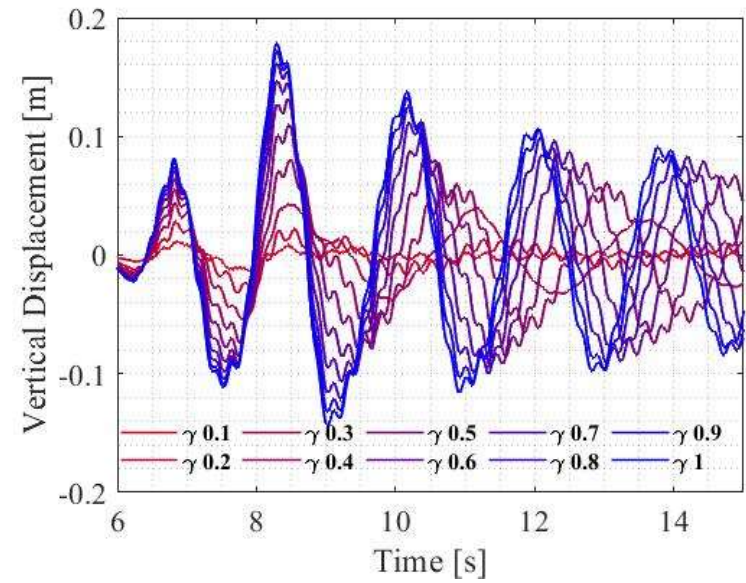

(a)

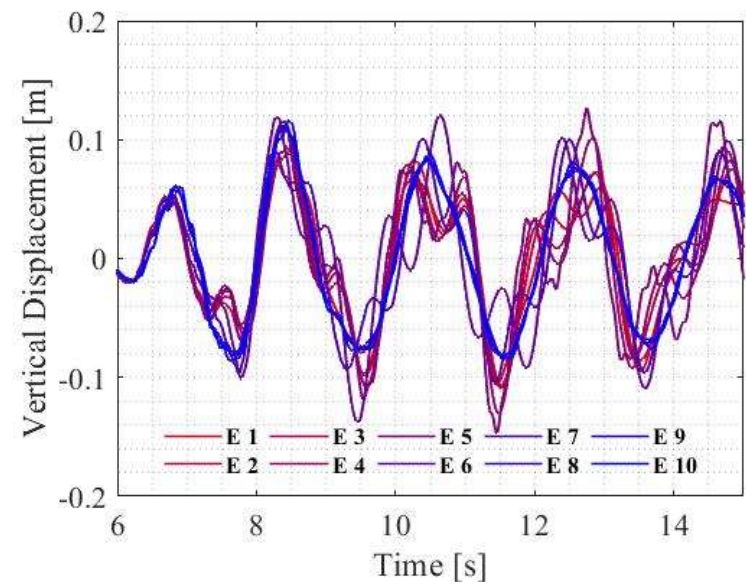

(c)

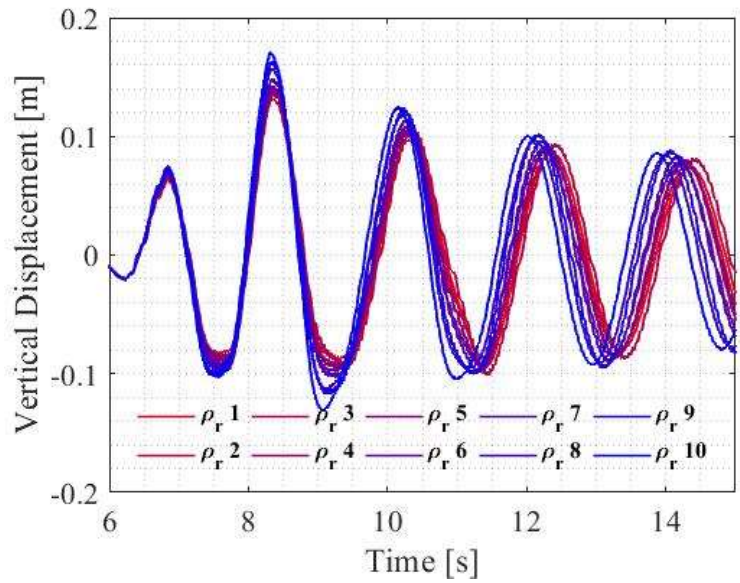

(b)

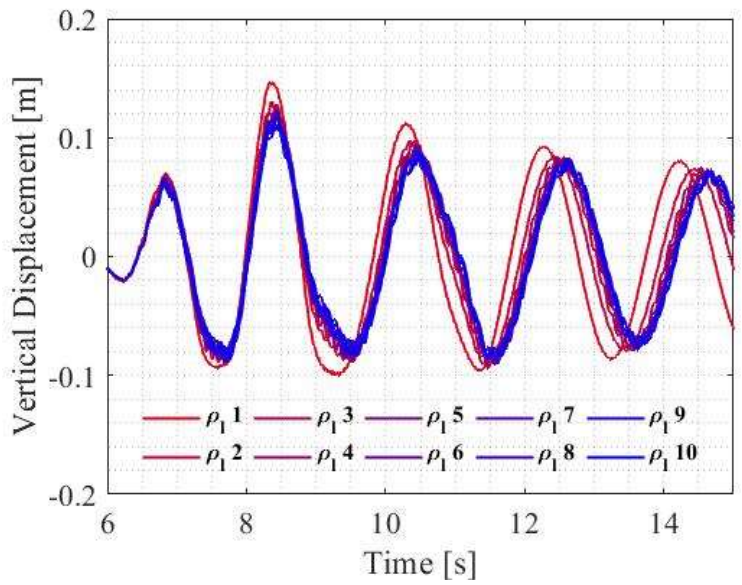

(d)

Fig. 14. Vertical displacement histories computed by the simplified model for (a) different $H / R$ ratios, (b) different $\rho_{\mathrm{r}},(\mathrm{c})$ different $\mathrm{E}$ and (d) different $\rho_{\mathrm{l}}$.

\section{Conclusions}

We developed a refined FE three-dimensional model of a scaled steel storage tank with a floating roof set in the Abaqus software. As an alternative approach, a simplified model that allows for computationally efficient simulation of the response history of the floating roof has been developed. Whilst the refined FE model achieved accurate results, it entailed a significant modelling effort and proved to be extremely timeconsuming from a computational viewpoint. Conversely, the simplified model required particular attention in input data definition, especially due to the presence of the annular ring, which can affect the vertical 
dynamics of the floating roof. Nonetheless, both the refined FE model and the simplified model provided quite similar response histories for vertical displacements of the roof at the edge of the tank wall. In the refined FE model, only slight delamination between the floating roof bottom surface and the fluid surface was observed. For the investigated tank, this validated the assumption of perfect contact between the bottom surface of the floating roof and the fluid surface, which was adopted in the case of the simplified model.

To assist in the models' calibration and validation, shaking table tests were carried out on a scaled steel storage tank equipped with a floating roof, subject to natural seismic ground motion. The experimental test provided very useful and rare experimental data concerning the dynamic response of the floating roof under seismic loading. From the shaking table test, it was obvious that relatively weak ground motion caused spillage of liquid out of the tank. This phenomenon was adequately simulated by the FE model as well as by the simplified model, which makes the simplified model attractive for seismic risk studies that account for record-to-record randomness.

Although results from both models agree with the experimental data observed for the particular tank investigated in this study, more studies are needed to further validate the models presented here and to better understand the limitations and seismic performance of the floating roofs of liquid storage tanks. Moreover, further studies are needed to validate closed-form solutions for peak vertical displacement of the floating roofs. A simple parametric study highlighted the strong influence of the $\gamma$ ratio on peak vertical floating roof displacement as compared to the other parameters investigated. Variation of the floating roof's Young's modulus negligibly affected maximum vertical displacement and was relevant mostly to the free vibration range with larger response variation. Finally, it was found that a simplified closed-form solution for peak vertical displacement can be sufficiently accurate, but this conclusion should be confirmed with response history analyses of floating roofs for a large variety of ground motions and a variety of storage tanks equipped with floating roofs.

\section{Acknowledgements}

The work presented herein was carried out with a financial grant from the H2020 Marie Skłodowska-Curie Innovative Training Network, within the research project XP-RESILIENCE (G.A. 721816). The second and third author have received funding from the Italian Ministry of Education, University and Research (MIUR) in the frame of the Departments of Excellence (grant L. 232/2016). The corresponding author acknowledges funding from the Slovenian Research Agency (Research Program Earthquake Engineering).

Finally, all the authors acknowledge CEA Seismic Mechanic Studies Laboratory in Saclay (France), who carried out the shaking table tests and provided the test data of broad tanks.

\section{Appendix}

In this appendix, the additional mathematical background and the mathematical derivations related to the components of Eq. (11) of the simplified model introduced in Section 3 are presented. Eq. (11) represents the governing equation of a multi-degree-of-freedom system in which the mass matrix includes the floating roof mass $\boldsymbol{P}$ and the added mass due to the fluid $\rho \boldsymbol{T} \boldsymbol{S}^{-\mathbf{1}} \boldsymbol{T}^{\boldsymbol{t}}$, and the same occurs for the stiffness matrix part $\boldsymbol{Q}$ and $\rho g \boldsymbol{U}$, respectively. 
$\boldsymbol{P}$ is the first part of the first term of Eq. (11) and represents the floating roof mass matrix which has the following indicial form:

$P_{i j}=-m \int_{0}^{2 \pi} \int_{0}^{R} \xi_{i} \xi_{j} r d r d \theta$

where $m$ stands for the floating roof unit mass and $\xi$ are interpolation functions used to describe the deformed shape of the floating roof. In this particular case, the interpolation functions are the mode shape functions of the floating roof in the air [25]:

$$
\begin{aligned}
& \xi_{0,1}(\mathrm{r}, \theta)=2 \frac{\mathrm{r}}{\mathrm{R}} \cos \theta \\
& \xi_{j, p}(r, \theta)=D_{j, p}\left[J_{p}\left(\lambda_{j, p} r / R\right)+E_{j, p} I_{p}\left(\lambda_{j, p} r / R\right)\right] \cos (p \theta)
\end{aligned}
$$

where $R$ is the floating roof radius, the index $j$ represents the nodal circumference number, and $p$ is the nodal diameter number. A few examples of modal shapes are presented in Fig. 15.

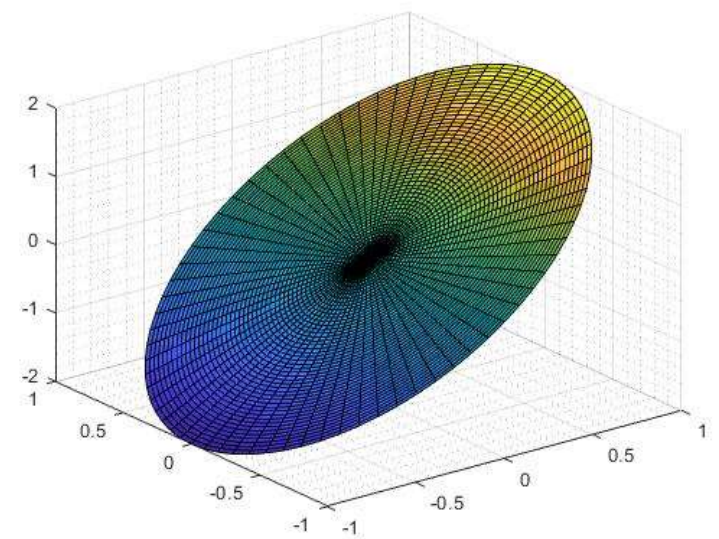

(a)

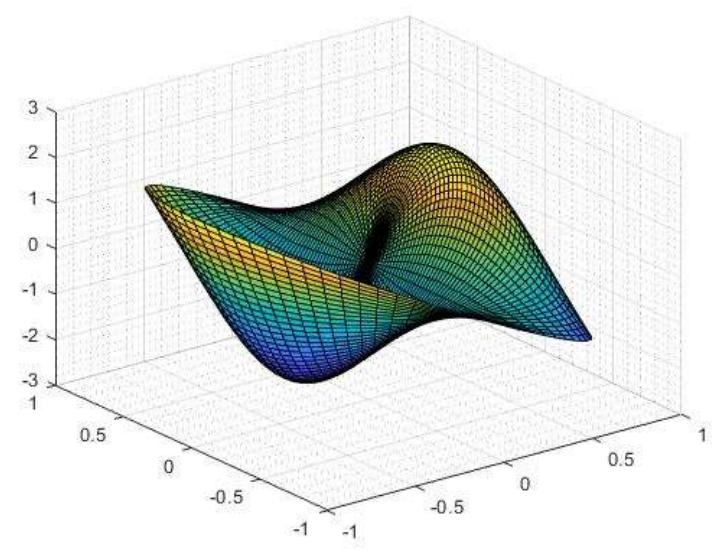

(c)

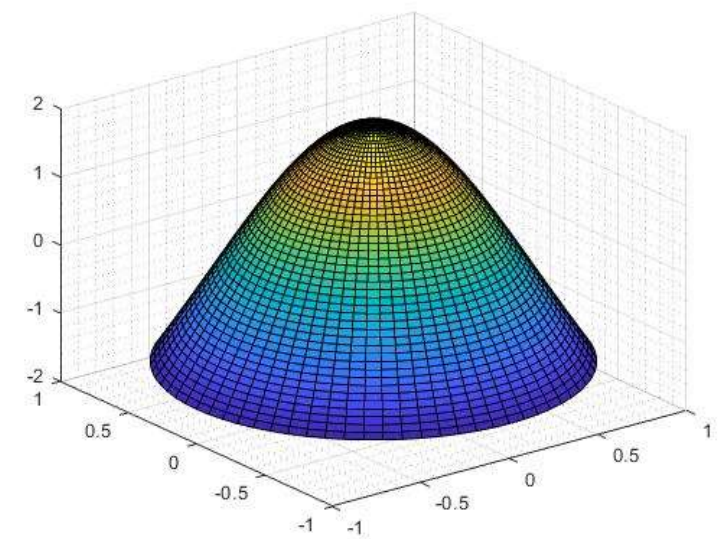

(b)

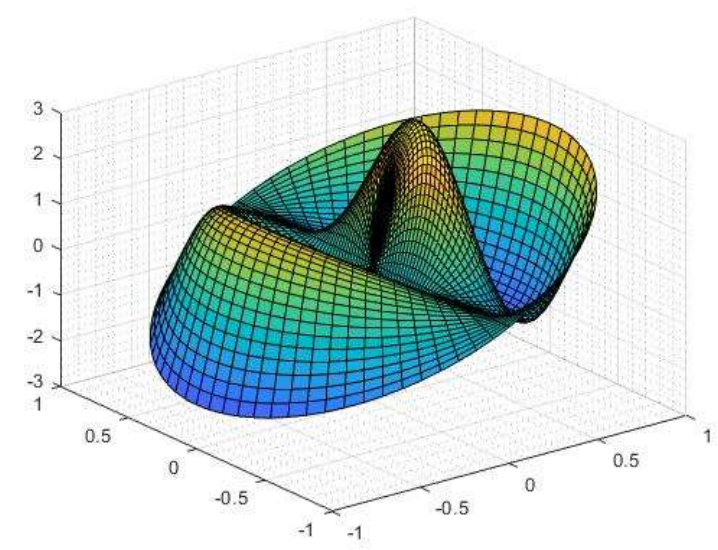

(d)

Fig. 15. Free edge circular plate modal shapes (a) $p=1$ and $j=0$ (b) $p=0$ and $j=1$ (c) $p=1$ and $j=1$ (d) $p=1$ and $j=2$. 
However, as highlighted in [17], it is worth noting that only rigid and elastic radial mode shapes are considered in the formulation. Hence, subscript $p$ is equal to 1 while subscript $j=0,1, \ldots, \mathrm{n}$. In this particular case, when $p=1$ and $j=0$, (see Eq.(A.2)), the free edge plate experiences a rigid-body mode with zero frequency, which means rigid rotation about the diameter, while the other modal shapes are described by Eq. (A.3), [25]. In this respect, for simplicity, subscript $p$ will be removed by notation since it will be assumed to be always unitary.

In Eq. (A.3) the frequency parameter $\left(\lambda_{j, p}\right)$ and the mode shape parameter $\left(E_{j, p}\right)$ are obtained by the eigenvalue problem while the amplitude parameter $\left(D_{j, p}\right)$ is derived by imposing the normalization as explained in the following: $J_{p}$ and $I_{p}$ are a Bessel function of the first kind of order $p$ and a modified Bessel function of order $p$, respectively.

The solution of the eigenvalue problem of a thin plate with free edges as boundary conditions makes it possible to compute $\lambda_{j, p}$ and $E_{j, p}[25]$ :

$$
\left\{\begin{array}{l}
E_{j, p}=\frac{\lambda_{j, p}^{2} J_{p}\left(\lambda_{j, p}\right)+(1-v)\left[\lambda_{j, p} J_{p}^{\prime}\left(\lambda_{j, p}\right)-p^{2} J_{p}\left(\lambda_{j, p}\right)\right]}{\lambda_{j, p}^{2} I_{p}\left(\lambda_{j, p}\right)-(1-v)\left[\lambda_{j, p} I_{p}^{\prime}\left(\lambda_{j, p}\right)-p^{2} I_{p}\left(\lambda_{j, p}\right)\right]} \\
E_{j, p}=\frac{\lambda_{j, p}^{3} J_{p}^{\prime}\left(\lambda_{j, p}\right)+p^{2}(1-v)\left[\lambda_{j, p} J_{p}^{\prime}\left(\lambda_{j, p}\right)-J_{p}\left(\lambda_{j, p}\right)\right]}{\lambda_{j, p}^{3} I_{p}^{\prime}\left(\lambda_{j, p}\right)-p^{2}(1-v)\left[\lambda_{j, p} I_{p}^{\prime}\left(\lambda_{j, p}\right)-I_{p}\left(\lambda_{j, p}\right)\right]}
\end{array}\right.
$$

The amplitude parameter $D_{j, p}$ from Eq.(A.3) is computed by imposing the shape function to be normal with respect of the mass Eq. (A.5), [25]:

$\int_{0}^{2 \pi} \int_{0}^{R} \rho h \xi_{j, p}^{2}(r, \theta) r d r d \theta=\pi \rho h R^{2}$

where $\rho$ is the plate density, $h$ is the plate thickness and $R$ is the plate radius. Substituting Eq. (A.3) in the left-hand side part of Eq. (A.5) and integrating over $\theta$ leads to Eq. (A.6):

$$
\begin{aligned}
& \int_{0}^{2 \pi} \rho h D_{j, p}^{2}\left\{\left[J_{p}\left(\lambda_{j, p} r / R\right)+E_{j, p} I_{p}\left(\lambda_{j, p} r / R\right)\right]\right\}^{2} \cos ^{2}(p \theta) r d \theta=\rho h D_{j, p}^{2}\left\{\left[J_{p}\left(\lambda_{j, p} r / R\right)+\right.\right. \\
& \left.\left.E_{j, p} I_{p}\left(\lambda_{j, p} r / R\right)\right]\right\}^{2} r\left(\pi+\frac{\sin (4 p \pi)}{4 p}\right)
\end{aligned}
$$

Because $p$ is always an integer, Eq. (A.6) becomes:

$$
\begin{aligned}
& \int_{0}^{2 \pi} \rho h D_{j, p}^{2}\left\{\left[J_{p}\left(\lambda_{j, p} r / R\right)+E_{j, p} I_{p}\left(\lambda_{j, p} r / R\right)\right]\right\}^{2} \cos ^{2}(p \theta) r d \theta=\pi \rho h D_{j, p}^{2}\left\{\left[J_{p}\left(\lambda_{j, p} r / R\right)+\right.\right. \\
& \left.\left.E_{j, p} I_{p}\left(\lambda_{j, p} r / R\right)\right]\right\}^{2} r
\end{aligned}
$$

The right-hand side of Eq. (A.7) can now be integrated (for $p \geq 0$ ) with respect to variable $r$ (Eq. (A.8)). It is worth noting that, since $\pi, \rho, h, D_{j, p}^{2}$ are $r$-independent, they can be extracted from the integral.

$$
\begin{aligned}
& \pi \rho h D_{j, p}^{2} \int_{0}^{R}\left\{\left[J_{p}\left(\lambda_{j, p} r / R\right)+E_{j, p} I_{p}\left(\lambda_{j, p} r / R\right)\right]\right\}^{2} r d r=\pi \rho h D_{j, p}^{2} R^{2} \frac{1}{2 \lambda_{j, p}}\left\{-E_{j, p}^{2} \lambda_{j, p} I_{p-1}^{2}\left(\lambda_{j, p}\right)+\right. \\
& E_{j, p}^{2} \lambda_{j, p} I_{p}^{2}\left(\lambda_{j, p}\right)+\lambda_{j, p} J_{p-1}^{2}\left(\lambda_{j, p}\right)+\lambda_{j, p} J_{p}^{2}\left(\lambda_{j, p}\right)+2 E_{j, p} I_{p-1}\left(\lambda_{j, p}\right)\left[p E_{j, p} I_{p}\left(\lambda_{j, p}\right)+J_{p}\left(\lambda_{j, p}\right)-\right. \\
& \left.\left.2 J_{p-1}\left(\lambda_{j, p}\right)\left(E_{j, p} I_{p}\left(\lambda_{j, p}\right)+p J_{p}\left(\lambda_{j, p}\right)\right)\right]\right\}
\end{aligned}
$$


The right-hand side of Eq. (A.8) can be written in a simplified manner (Eq. (A.9)):

$\pi \rho h D_{j, p}^{2} R^{2} \frac{1}{2 \lambda_{j, p}}\left\{-E_{j, p}^{2} \lambda_{j, p} I_{p-1}^{2}\left(\lambda_{j, p}\right)+E_{j, p}^{2} \lambda_{j, p} I_{p}^{2}\left(\lambda_{j, p}\right)+\lambda_{j, p} J_{p-1}^{2}\left(\lambda_{j, p}\right)+\lambda_{j, p} J_{p}^{2}\left(\lambda_{j, p}\right)+\right.$
$\left.2 E_{j, p} I_{p-1}\left(\lambda_{j, p}\right)\left[p E_{j, p} I_{p}\left(\lambda_{j, p}\right)+J_{p}\left(\lambda_{j, p}\right)-2 J_{p-1}\left(\lambda_{j, p}\right)\left(E_{j, p} I_{p}\left(\lambda_{j, p}\right)+p J_{p}\left(\lambda_{j, p}\right)\right)\right]\right\}=M D_{j, p}^{2} X$

where $M$ and $X$ are defined by Eq. (A.10) and Eq. (A.11), respectively. It is worth noting that $M$ represents the total mass of the floating roof.

$M=\pi \rho h R^{2}$

$X=\frac{1}{2 \lambda_{j, p}}\left\{-E_{j, p}^{2} \lambda_{j, p} I_{p-1}^{2}\left(\lambda_{j, p}\right)+E_{j, p}^{2} \lambda_{j, p} I_{p}^{2}\left(\lambda_{j, p}\right)+\lambda_{j, p} J_{p-1}^{2}\left(\lambda_{j, p}\right)+\lambda_{j, p} J_{p}^{2}\left(\lambda_{j, p}\right)+\right.$

$\left.2 E_{j, p} I_{p-1}\left(\lambda_{j, p}\right)\left[p E_{j, p} I_{p}\left(\lambda_{j, p}\right)+J_{p}\left(\lambda_{j, p}\right)-2 J_{p-1}\left(\lambda_{j, p}\right)\left(E_{j, p} I_{p}\left(\lambda_{j, p}\right)+p J_{p}\left(\lambda_{j, p}\right)\right)\right]\right\}$

Imposing the normalization with respect to the total plate mass, it is now possible to solve Eq. (A.12) with respect to the amplitude parameter $D_{j, p}^{2}$. Eq. (A.12) will provide two opposite values. For the amplitude parameter, the positive value must be selected.

$M D_{j, p}^{2} X=M(\mathrm{~A} .12)$

The matrix $\rho \boldsymbol{T} \boldsymbol{S}^{-\mathbf{1}} \boldsymbol{T}^{\boldsymbol{t}}$ in the second part of the first term of Eq. (11) represents the fluid mass excited during the convective motion. Their indicial forms are provided by the following equations:

$S_{i j}=\int_{0}^{R}\left[\frac{\epsilon_{j} J_{1}\left(\frac{\epsilon_{j}}{R} r\right)}{2 R J_{1}\left(\epsilon_{j}\right)} \tanh \left(\frac{\epsilon_{j}}{R} H\right) \frac{J_{1}\left(\frac{\epsilon_{i}}{R} r\right)}{J_{1}\left(\epsilon_{i}\right)}+\frac{\epsilon_{i} J_{1}\left(\frac{\epsilon_{i}}{R} r\right)}{2 R J_{1}\left(\epsilon_{i}\right)} \tanh \left(\frac{\epsilon_{i}}{R} H\right) \frac{J_{1}\left(\frac{\epsilon_{j}}{R} r\right)}{J_{1}\left(\epsilon_{j}\right)}\right] r d r$

$T_{i j}=\int_{0}^{2 \pi} \int_{0}^{R} \xi_{i} \frac{J_{1}\left(\frac{\epsilon_{j}}{R} r\right)}{J_{1}\left(\epsilon_{j}\right)} \cos \theta r d r d \theta$

where $J_{1}$ is a Bessel function of the first type of order one and $\epsilon_{i}$ is the $\mathrm{i}^{\text {th }}$ root of the first derivative of a Bessel function of the first type of order one, as in Eq. (A.15).

$J^{\prime}{ }_{1}\left(\epsilon_{i}\right)=0$

Matrices $\boldsymbol{Q}$ and $\boldsymbol{U}$ in Eq. (11) represent the stiffness matrix of the floating roof and the contribution of the fluid to the stiffness of the coupled floating roof-fluid system, respectively, whose indicial form is defined in Eq. (A.16) and (A.17).

$$
\begin{aligned}
& Q_{i j}=\frac{E h^{3}}{12\left(1-v^{2}\right)} \int_{0}^{2 \pi} \int_{0}^{R}\left(\xi_{i, r r} \xi_{j, r r}+\frac{v}{r^{2}} \xi_{i, r r} \xi_{j, \theta \theta}+\frac{v}{r} \xi_{j, r} \xi_{i, r r}+\frac{1}{r^{4}} \xi_{j, \theta \theta} \xi_{i, \theta \theta}+\frac{1}{r^{3}} \xi_{j, \theta \theta} \xi_{i, r}+\frac{1}{r^{3}} \xi_{j, r} \xi_{i, \theta \theta}+\right. \\
& \left.\frac{1}{r^{2}} \xi_{j, r} \xi_{i, r}+\frac{v}{r^{2}} \xi_{j, r r} \xi_{i, \theta \theta}+\frac{v}{r} \xi_{j, r r} \xi_{i, r}\right) r d r d \theta+\frac{E h^{3}}{24(1+v)} \int_{0}^{2 \pi} \int_{0}^{R}\left(\frac{4}{r^{2}} \xi_{j, r \theta} \xi_{i, r \theta}-\frac{4}{r^{3}} \xi_{j, r \theta} \xi_{i, \theta}-\frac{4}{r^{3}} \xi_{j, \theta} \xi_{i, r \theta}+\right. \\
& \left.\frac{4}{r^{4}} \xi_{j, \theta} \xi_{i, \theta}\right) r d r d \theta \\
& U_{i j}=\int_{0}^{2 \pi} \int_{0}^{R} \xi_{i} \xi_{j} r d r d \theta
\end{aligned}
$$


$E$ and $v$ are the Young modulus and the Poisson ratio of the floating roof material, respectively, while $h$ is the floating roof thickness. $\xi$ is the interpolating function of Eq. (A.2) or Eq. (A.3) and subscripts after the comma represent the derivative with respect to the subscripts themselves.

$\chi$ matrix in Eq. (11) is defined by Eq. (A.18). It accounts for the large deflection of the floating roof using a cubic stiffness term [23].

$$
\begin{aligned}
& \chi_{l m n i}=\frac{E h}{1-v^{2}} \int_{0}^{2 \pi} \int_{0}^{R}\left(\sum_{j=1}^{I} \eta_{j, r} \Psi_{l m j} \xi_{n, r} \xi_{i, r}+\frac{1}{2} \xi_{l, r} \xi_{m, r} \xi_{n, r} \xi_{i, r}+\right. \\
& \frac{v}{2 r^{2}} \xi_{l, \theta} \xi_{m, \theta} \xi_{n, r} \xi_{i, r} \sum_{j=1}^{I} \eta_{j, r} \Psi_{l m j} \xi_{n, r} \xi_{i, r}+\frac{1}{2} \xi_{l, r} \xi_{m, r} \xi_{n, r} \xi_{i, r}+\frac{v}{2 r^{2}} \xi_{l, \theta} \xi_{m, \theta} \xi_{n, r} \xi_{i, r}+ \\
& \frac{v}{r} \sum_{j=1}^{I} \eta_{j} \Psi_{l m j} \xi_{n, r} \xi_{i, r}+\frac{1}{r^{3}} \sum_{j=1}^{I} \eta_{j} \Psi_{l m j} \xi_{n, \theta} \xi_{i, \theta}+\frac{1}{2 r^{4}} \xi_{l, \theta} \xi_{m, \theta} \xi_{n, \theta} \xi_{i, \theta}+\frac{v}{r^{2}} \sum_{j=1}^{I} \eta_{j, r} \Psi_{l m j} \xi_{n, \theta} \xi_{i, \theta}+ \\
& \left.\frac{v}{2 r^{2}} \xi_{l, r} \xi_{m, r} \xi_{n, \theta} \xi_{i, \theta}\right) r d r d \theta+\frac{E h}{2(1+v)} \int_{0}^{2 \pi} \int_{0}^{R}\left(\frac{1}{r^{2}} \sum_{j=1}^{I} \eta_{j, \theta} \Psi_{l m j} \xi_{n, \theta} \xi_{i, r}+\frac{1}{r^{2}} \sum_{j=1}^{I} \eta_{j, \theta} \Psi_{l m j} \xi_{n, r} \xi_{i, \theta}+\right. \\
& \left.\frac{1}{r^{2}} \xi_{l, r} \xi_{m, \theta} \xi_{n, \theta} \xi_{i, r}+\frac{1}{r^{2}} \xi_{l, r} \xi_{m, r} \xi_{n, \theta} \xi_{i, \theta}\right) r d r d \theta
\end{aligned}
$$

All the terms in Eq. (A.18) have the same meaning as the aforementioned terms. The only novelties are represented by the introduction of Eq. (A.19) and the terms $\Psi_{l m j}$ presented in Eq. (A.20).

$\eta_{i}(r, \theta)=\sin \left(\lambda_{i} \frac{r}{R}\right) \cos \theta$

Eq. (A.19), similarly to Eqs. (A.2) and (A.3), is an interpolation function, which is used to describe the radial deflection in the midplane of the floating roof. $\Psi_{l m j}$ can instead be calculated using Eqs. (A.21) and (A.22).

$\sum_{j=1}^{J}-\left[H_{i j}\right]^{-1} \sum_{l=1}^{I} \sum_{k=1}^{I} \Gamma_{l k j} B_{l} B_{k}=\sum_{l=1}^{I} \sum_{k=1}^{I} \Psi_{l k j} B_{l} B_{k}$

$H_{i j}=\frac{E h}{1-v^{2}} \int_{0}^{2 \pi} \int_{0}^{R}\left(\eta_{j, r} \eta_{i, r}+\frac{v}{r} \eta_{j} \eta_{i, r}+\frac{1}{r^{2}} \eta_{j} \eta_{i}+\frac{v}{r} \eta_{j, r} \eta_{i}\right) r d r d \theta+\frac{E h}{2(1+v)} \int_{0}^{2 \pi} \int_{0}^{R} \frac{1}{r^{2}} \eta_{j, \theta} \eta_{i, \theta} r d r d \theta$

$\Gamma_{l k i}=\frac{E h}{1-v^{2}} \int_{0}^{2 \pi} \int_{0}^{R}\left(\frac{1}{2} \xi_{l, r} \xi_{k, r} \eta_{i, r}+\frac{v}{2 r^{2}} \xi_{l, \theta} \xi_{k, \theta} \eta_{i, r}+\frac{1}{2 r^{3}} \xi_{l, \theta} \xi_{k, \theta} \eta_{i}+\frac{v}{2 r} \xi_{l, r} \xi_{k, r} \eta_{i}\right) r d r d \theta+$ $\frac{E h}{2(1+v)} \int_{0}^{2 \pi} \int_{0}^{R} \frac{1}{r^{2}} \xi_{l, r} \xi_{k, \theta} \eta_{i, \theta} r d r d \theta$

The last term of Eq. (11) is the vector $\boldsymbol{G}$. It is described in Eq. (A.23), where all the terms have already been described.

$G_{i}=\int_{0}^{2 \pi} \int_{0}^{R} \xi_{i} r^{2} \cos \theta d r d \theta$ 


\section{References}

[1] National Institute of Standard and Technology, "A study of the performance of petroleum storage tanks during earthquakes, 1993-1995," Gaithersburg, Maryland, 1995.

[2] E. Brunesi, R. Nascimbene, M. Pagani, and D. Beilic, "Seismic performance of storage steel tanks during the May 2012 Emilia, Italy, Earthquakes," J. Perform. Constr. Facil., vol. 29, no. 5, pp. 19, 2015.

[3] U.S. Environmental Protection Agency, "Control of Volatile Organic Emissions from Petroleum Liquid Storage in External Floating Roof Tanks.” Springfield, Virginia, 1978.

[4] U.S. Environmental Protection Agency, “AP-42,” vol. 1. 1995.

[5] P. K. Malhotra, "Base uplifting analysis of flexibly supported liquid-storage tanks," Earthq. Eng. Struct. Dyn., vol. 24, no. 12, pp. 1591-1607, 1995.

[6] P. K. Malhotra, "Seismic response of soil-supported unanchored liquid-storage tanks," no. 2, pp. 3043-3045, 1997.

[7] P. K. Malhotra, T. Wenk, and M. Wieland, "Simple procedure for seismic analysis of liquid-storage tanks," Struct. Eng. Int. J. Int. Assoc. Bridg. Struct. Eng., vol. 10, no. 3, pp. 197-201, 2000.

[8] H. N. Phan, F. Paolacci, and S. Alessandri, "Fragility Analysis Methods for Steel Storage Tanks in Seismic Prone Areas,” Vol. 8 Seism. Eng., vol. 00032, no. July, p. V008T08A023, 2016.

[9] M. Vathi, S. A. Karamanos, I. A. Kapogiannis, and K. V. Spiliopoulos, "Performance Criteria for Liquid Storage Tanks and Piping Systems Subjected To Seismic Loading," J. Press. Vessel Technol., pp. 1-12, 2017.

[10] S. Alessandri, A. C. Caputo, D. Corritore, R. Giannini, F. Paolacci, and H. N. Phan, "Probabilistic risk analysis of process plants under seismic loading based on Monte Carlo simulations," J. Loss Prev. Process Ind., vol. 53, no. December 2017, pp. 136-148, 2018.

[11] K. Bakalis and D. Vamvatsikos, "Seismic Vulnerability Assessment for Liquid Storage," pp. 1-10, 2018.

[12] A. Kozak, P. J. Cacciatore, and L. M. Gustafsson, "Seismic response of floating roof liquid storage tanks part II. Contact pressure approach.," in ASME 2010 Pressure Vessels \& Piping Division / KPVP Conference, 2010.

[13] Y. Yamauchi, A. Kamei, S. Zama, and Y. Uchida, "Seismic design of floating roof of oil storage tanks under liquid sloshing," in ASME Pressure Vessels and Piping Division Conference, 2006, vol. 2006, pp. 1-9.

[14] M. A. Goudarzi, "Seismic Design of a Double Deck Floating Roof Type Used for Liquid Storage Tanks," J. Press. Vessel Technol. Trans. ASME, vol. 137, no. 4, pp. 1-7, 2015.

[15] T. Matsui, "Sloshing in a Cylindrical Liquid Storage Tank With a Floating Roof Under Seismic Excitation," J. Press. Vessel Technol., vol. 129, no. 4, p. 557, 2007.

[16] F. Sakai, M. Nishimura, and H. Ogawa, "Sloshing behavior of floating-roof oil storage tanks," Comput. Struct., vol. 19, no. 1-2, pp. 183-192, 1984. 
[17] R. Shabani, "Stress Patterns in Single Deck Floating Roofs Subjected to Ground Motion Accelerations," Int. J. Eng. J, vol. 26, no. 12, pp. 1495-1504, 2013.

[18] K. Hatayama, S. Zama, and S. Yoshida, "Measurement of natural frequencies of the fluidelasticcoupled shell plate vibration of a large-sized cylindrical steel tank by microtremor observation," Am. Soc. Mech. Eng. Press. Vessel. Pip. Div. PVP, vol. 8, no. 1, pp. 1-9, 2018.

[19] Commissariat a L'energie Atomique et Aux Energies Alternatives, "Component Fragility Evaluation, Seismic Safety Assessment And Design Of Petrochemical Plants Under Design-Basis And Beyond-Design-Basis Accident Conditions (INDUSE-2-SAFETY)," no. July. Saclay, France, pp. 1-59, 2017.

[20] B. Molin and F. Remy, "Experimental and numerical study of the sloshing motion in a rectangular tank with a perforated screen," J. Fluids Struct., vol. 43, pp. 463-480, 2013.

[21] M. Hosseini, M. A. Goudarzi, and A. Soroor, "Reduction of seismic sloshing in floating roof liquid storage tanks by using a Suspended Annular Baffle (SAB)," J. Fluids Struct., vol. 71, pp. 40-55, 2017.

[22] J. Radnić, N. Grgić, M. Sunara Kusić, and A. Harapin, "Shake table testing of an open rectangular water tank with water sloshing," J. Fluids Struct., vol. 81, pp. 97-115, 2018.

[23] R. Shabani and F. G. Golzar, "Large deflection analysis of floating roofs subjected to earthquake ground motions," Nonlinear Anal. Real World Appl., vol. 13, no. 5, pp. 2034-2048, 2012.

[24] Dassault Systemes, “ABAQUS/CAE.” Pawtucket, RI : ABAQUS, 2019.

[25] K. Itao and S. H. Crandall, "Natural Modes and Natural Frequencies of Uniform, Circular, FreeEdge Plates," J. Appl. Mech., vol. 46, no. June 1979, pp. 448-453, 1979.

[26] MathWorks, "MATLAB the Language of Technical Computing." The MathWorks, Inc., Natick, Massachusetts, United States, 2012.

[27] L. F. Shampine and M. W. Reichelt, "The Matlab ODE Suite." The MathWorks, Inc., Natick, Massachusetts, United States, pp. 1-22.

[28] J. R. Dormand and P. J. Prince, "A reconsideration of some embedded Runge-Kutta formulae," $J$. Comput. Appl. Math., vol. 15, no. 2, pp. 203-211, 1986.

[29] A. Constantinescu, A. E. M. Alaoui, A. Nême, N. Jacques, and P. Rigo, "Numerical and experimental studies of simple geometries in slamming," Int. J. Offshore Polar Eng., vol. 21, no. 3, pp. 216-224, 2011.

[30] A. Dorogoy, D. Rittel, and A. Brill, "Experimentation and modeling of inclined ballistic impact in thick polycarbonate plates," Int. J. Impact Eng., vol. 38, no. 10, pp. 804-814, 2011.

[31] J. C. Crittenden, R. R. Trussell, D. W. Hand, K. J. Howe, and G. Tchobanoglous, MWH's Water Treatment: Principles and Design: Third Edition. 2012.

[32] J. D. Cutnell and K. W. Johnson, Physics, 8th ed. Danvers, MA, 2009.

[33] M. Hosseini, A. Soroor, A. Sardar, and F. Jafarieh, "A simplified method for seismic analysis of tanks with floating roof by using finite element method: Case study of Kharg (Southern Iran) island tanks," Procedia Eng., vol. 14, pp. 2884-2890, 2011. 
[34] H. Nishi, M. Yamada, S. Zama, K. Hatayama, and K. Sekine, "Experimental Study on the Sloshing Behavior of the Floating Roof using a Real Tank," J. High Press. Inst. Japan, vol. 46, no. 1, pp. 417, 2008.

[35] F. Tornabene, Meccanica delle Strutture a Guscio in Materiale Composito. Il Metodo Generalizzato di Quadratura Differenziale. Società Editrice Esculapio, 2012.

[36] R. Huston and H. Josephs, "Practical stress analysis in engineering design, third edition," Pract. Stress Anal. Eng. Des. Third Ed., pp. 1-635, 2008. 